\title{
EFFECTS OF ESSENTIAL OILS ON THE PERFORMANCE, HEALTH, AND FEEDING BEHAVIOR OF GROWING CATTLE
}

A Thesis
presented to
the Faculty of the Graduate School
at the University of Missouri-Columbia
In Partial Fulfillment
of the Requirements for the Degree
Master of Science
HANNAH ALLEN
bric Bailey, Thesis Supervisor

July 2021 
The undersigned, appointed by the Associate Vice Chancellor of the Office of Research and Graduate Studies, have examined the thesis entitled

\section{EFFECTS OF ESSENTIAL OILS ON THE PERFORMANCE, HEALTH, AND FEEDING BEHAVIOR OF GROWING CATTLE}

presented by Hannah Allen, a candidate for the degree of Master of Science, and hereby certify that, in their opinion, it is worthy of acceptance.

Dr. Eric Bailey

Assistant Professor

Division of Animal Sciences

Dr. Derek Brake

Assistant Professor

Division of Animal Sciences

Dr. Harley Naumann

Associate Professor

Division of Plant Sciences 


\section{ACKNOWLEDGEMENTS}

I would like to say thank you to Dr. Eric Bailey for taking a chance on me as an undergraduate and giving me the opportunity to pursue a master's degree. I cannot say thank you enough for all of your guidance and the opportunities you have given me.

I would also like to say thank you to Dr. Derek Brake for being a part of my committee, but also for your guidance throughout the past 3 years, especially during the research experiments. Thank you to Dr. Harley Naumann for also serving on my committee and for the input in getting things wrapped up.

A special thank you to Josh Zeltwanger for all of his help during the experiments and guidance. Thank you for lending a helping hand and encouraging me to think. To the rest of the graduate students that helped when needed, Emily Petzel and Mikaela Adams, thank you, I have enjoyed getting to know you over the past 2-3 years.

Lastly, I would like to thank my family and friends for their love and support throughout my education. To my mom and grandparents, thank you for encouraging me always to pursue my dreams, and being there when needed, even when that includes driving 3 hours to bring me a vehicle. My siblings, even though we are all scattered around the country, thank you for being only a text or phone call away. Lily, I would not have been able to survive college without you and I am truly thankful to have you in my life. Dakota, thank you for your support and encouragement always. Thank you for always being understanding and supporting me in any decisions I have made. 


\section{TABLE OF CONTENTS}

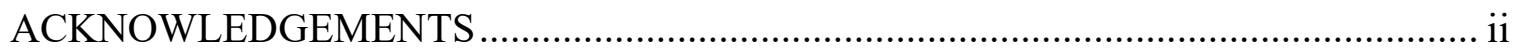

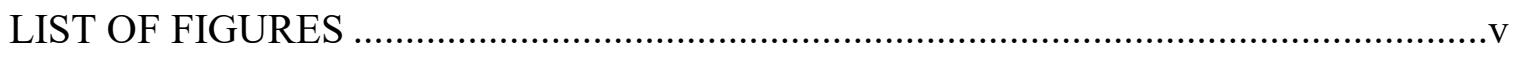

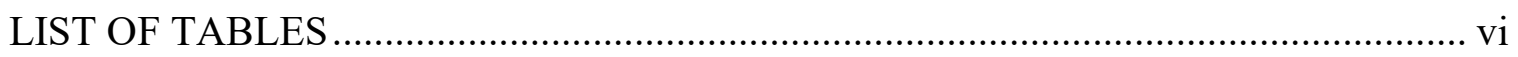

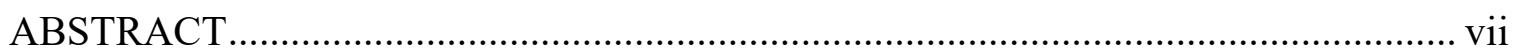

CHAPTER 1. REVIEW OF LITERATURE .................................................................

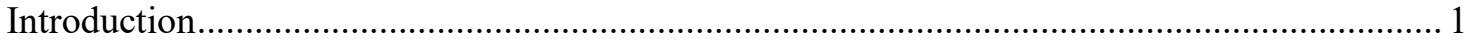

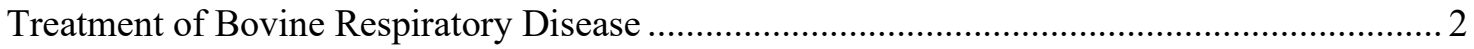

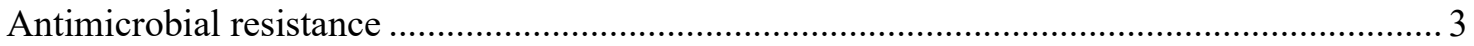

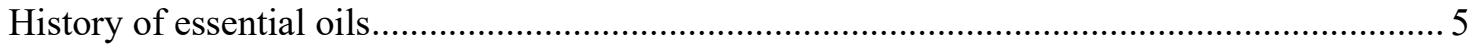

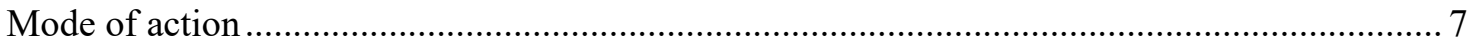

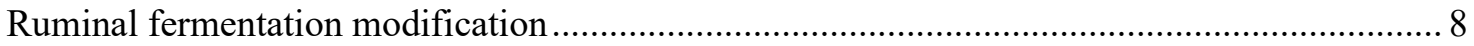

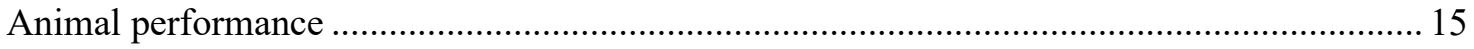

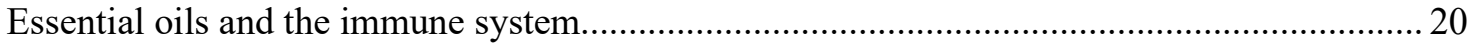

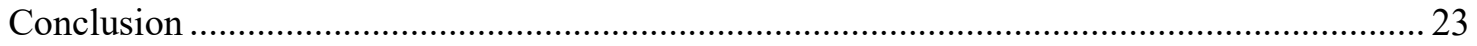

CHAPTER 2. EFFECT OF ESSENTIAL OILS ON PERFORMANCE AND HEALTH

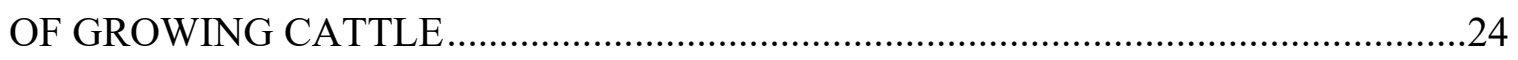

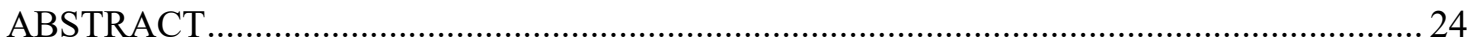

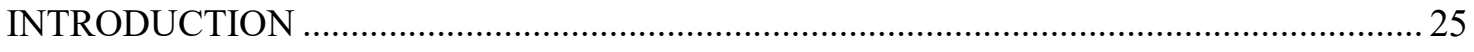

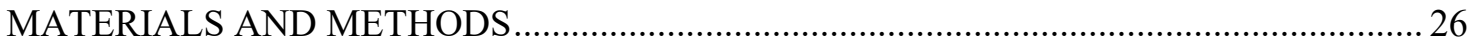

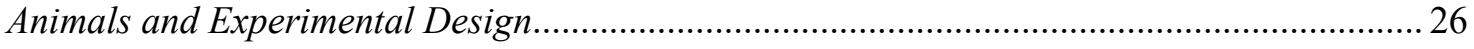

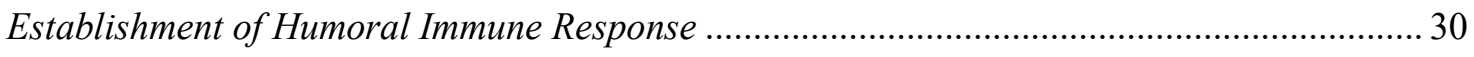

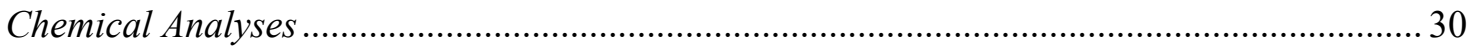

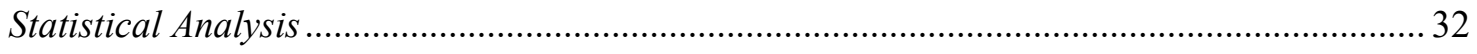

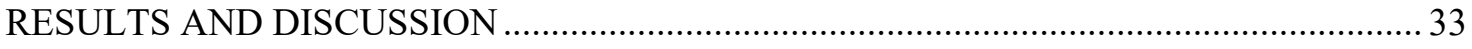

CONCLUSION

CHAPTER 3. EFFECTS OF ESSENTIAL OILS ON FEEDING BEHAVIOR OF

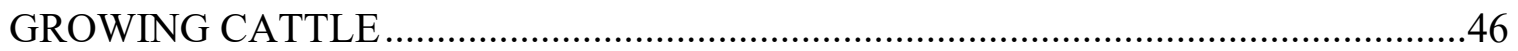

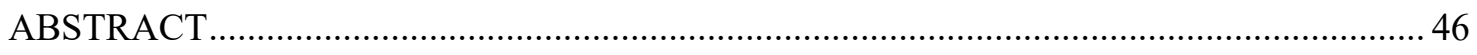

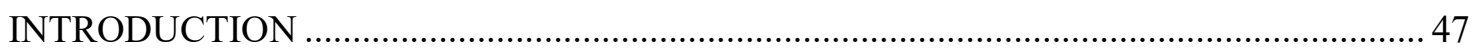

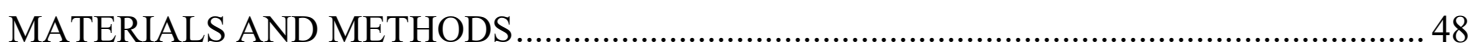

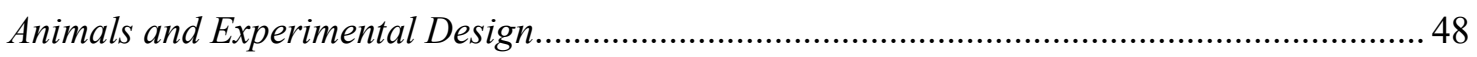

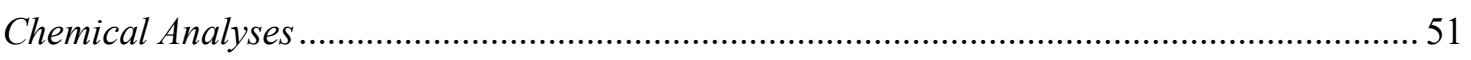




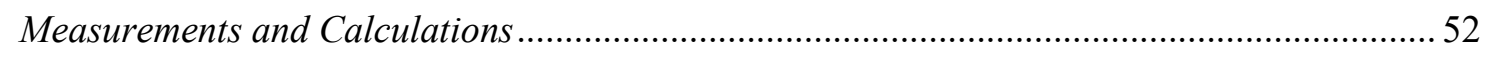

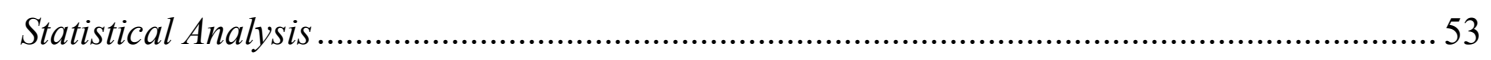

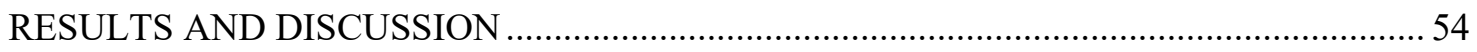

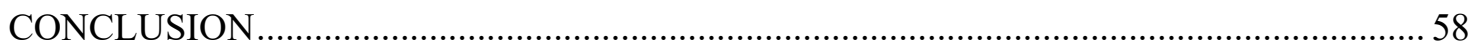

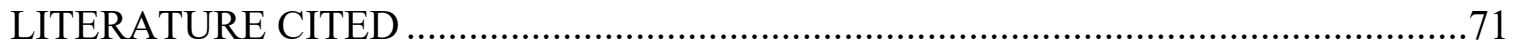




\section{LIST OF FIGURES}

Figure

Page

Figure 3.1. Frequency distribution of log normal interval length between visits to bunks.

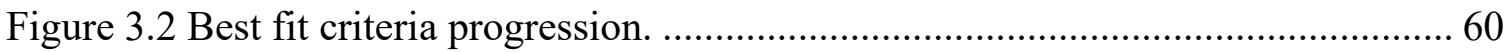

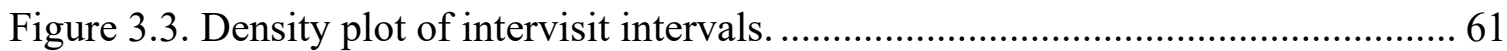

Figure 3.4. Effect of essential oils (EO) or control (CON) on daily dry matter intake of growing beef cattle fed a complete feed

Figure 3.5. Effect of essential oils(EO) or control $(\mathrm{CON})$ on dry matter intake per meal in growing beef cattle fed a complete feed

Figure 3.6. Effect of essential oils (EO) or control (EO) on feeding rate of growing beef cattle fed a complete feed.

Figure 3.7. Effect of essential oils (EO) or control (CON) on number of meals per day in growing beef cattle fed a complete feed

Figure 3.8. Effect of essential oils (EO) or control $(\mathrm{CON})$ on meal duration in growing beef cattle fed a complete feed.

Figure 3.9. Effect of essential oils $(\mathrm{EO})$ or control $(\mathrm{CON})$ on visit duration in growing beef cattle fed a complete feed.

Figure 3.10. Effect of essential oils (EO) or control (CON) on number of visits per meal in growing beef cattle fed a complete feed 70 


\section{LIST OF TABLES}

Table

Page

Table 2.1. Chemical composition of complete feed with essential oils (EO) or without essential oils (control)

Table 2.2. Effect of essential oils (EO) or control on performance in backgrounding steers

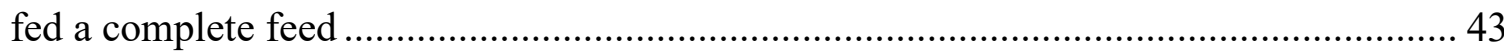

Table 2.3. Effect of essential oils (EO) or control on body weight in backgrounding steers

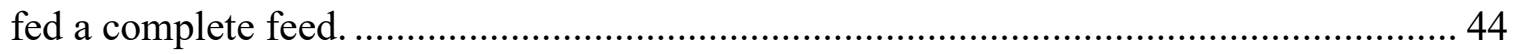

Table 2.4. Effect of essential oils (EO) or control on IgG Concentration and Area Under the Curve in backgrounding steers fed a complete feed.

Table 3.1. Chemical composition of complete feed with essential oils (EO) or without essential oils (control).

Table 3.2. Effect of essential oils (EO) or control on feeding behavior characteristics in growing beef cattle fed a complete feed. 


\begin{abstract}
Concerns and changes in policy related to use of antimicrobials in livestock has led to increased interest in using alternative feed additives such as essential oils (EO). Essential oils are plant secondary metabolites with characteristic odors. Essential oils are reported to alter ruminal fermentation (Hart et al., 2008) and animal performance (Calsamiglia et al., 2007). There is also evidence to suggest that EOs may manipulate feeding behavior in cattle (Tager and Krause, 2011). An experiment was conducted to evaluate the effects of a blend of EO in a commercially available complete feed (MFA Cattle Charge, MFA Inc., Columbia, MO) on performance, health, and feeding behavior of steers during the backgrounding phase. Eighty beef steers (initial BW $=267 \pm 2.6 \mathrm{~kg}$ ) were obtained from 3 different sources and assigned risk groups based on distance traveled, previous health management, and incidence of disease. Pen fed EO tended $(P=0.09)$ to have a greater DMI than control. After 56 days on feed, steers exposed to moderate stress and fed EO had greater BW than steers exposed to moderate stress and fed control, but EO had no impact on final BW among steers exposed to small or large amounts of stress. Addition of EO did not have an effect on concentrations of anti-egg albumin $\operatorname{IgG}(P=0.99)$. Under conditions of this experiment, inclusion of essential oils in a complete feed appeared to improve dry matter intake and weight gain in calves during the backgrounding phase. Meal intervals among calves in this study was 28 minutes and 40 seconds between the end time of a feeding event and start time of the next feeding event. Addition of EO to a complete feed influenced feeding rate through an interaction between treatment and days on feed $(P=0.02)$. Specifically, feeding rate was greater on days 11 and 44 in steers offered EO than steers offered control. Addition of EO to a complete feed may improve
\end{abstract}


animal performance, health, and feeding behavior but under the conditions of this experiment, cattle source influenced the response to EO supplementation. 


\section{CHAPTER 1. REVIEW OF LITERATURE}

\section{Introduction}

The multi-segmented nature of the beef industry contributes to health challenges for growing cattle as they transition from the ranch of origin through the feedlot system. The biggest segment of the beef industry is cow-calf operations, where producers breed cows to produce calves that will be used for future generations of cattle breeding or be sold to a backgrounding or feedlot operation.

After weaning, calves proceed from cow-calf operations to stocker, backgrounder, or feedlot operations where the end goal is harvest for beef. Stocker operations are forage-based growing programs for weaned calves where calves are allowed to graze forages. Backgrounding operations are growing programs where weaned calves are placed into a dry lot to grow on rations based around cost-effective feedstuffs. Both stocker and backgrounding operations are used to prepare weaned calves for future feedlot programs. There are fewer backgrounding and stocker operations compared to cow-calf operations, and even fewer feedlots.

When calves are marketed from the ranch of origin and placed into a stocker, backgrounding, or feedlot operation, they encounter a variety of stressors, including transportation, processing, comingling, diet changes, and environmental changes. These stressors can result in increases in morbidity and mortality along with decreased animal performance through decreased feed and water intake. Combinations of the stressors can 
impair a calf's immune response to infectious agents encountered when transitioning to a new environment.

The bovine respiratory disease complex (BRD) plagues the U.S. beef industry and represents pneumonia in cattle resulting from alveolar infections from infectious bovine rhinotracheitis, parainfluenza-3, bovine viral diarrhea virus, bovine respiratory syncytial virus, Histophilus somni, Mannheimia haemolytica, and Pasteurella multocida (Duff and Galyean, 2007; Wilson et al., 2017). It is estimated to cause approximately $75 \%$ of total morbidity found in the feedlots (Wilson et al., 2017). Woolums and others (2015) conducted a cross-sectional survey of 561 feedlots in 21 states and found that BRD was the leading cause of morbidity and mortality. These authors (Woolums et al., 2015) also estimated that BRD costs the beef industry more than $\$ 2$ billion dollars in economic losses annually (Wilson, 2014; Wilson et al., 2017).

Bovine respiratory disease is multifactorial. Commonly, stress that occurs during transition to a stocker, backgrounding, or feedlot operation, along with previous management, health, and genetics are all factors that can contribute to BRD (Duff and Galyean, 2007). Typically, severity of BRD infection is determined by the current immune status of the calf, and thus, highly stressed calves are more likely to be infected (Galyean et al., 1995).

\section{Treatment of Bovine Respiratory Disease}

Elimination of BRD in calves is unlikely, but management practices can be implemented to decrease its impact. Commonly, efforts to prevent disease among calves transitioning to stocker, backgrounding or feedlot programs includes preconditioning, 
vaccination, and metaphylactic medications. Preconditioning is the process of weaning calves and holding on the farm of origin for a period of time before marketing and transportation, along with a vaccination program, treatment with anthelmintics, dehorning, castration of intact males, and introducing calves to feed bunks and water troughs (Duff and Galyean, 2007). For purposes of reducing incidence of BRD, calves are vaccinated against viral and bacterial diseases.

Antimicrobials are administered to beef cattle for the treatment, prevention, and control of disease, and to enhance growth performance (Landers et al., 2012). Use of antimicrobials for treatment of disease in ill animals and to prevent disease from spreading when ill animals are present are common uses for antimicrobials in livestock production. The third major use of antimicrobials in livestock production is metaphylaxis and is used to control the spread of disease when animals are determined to be a high risk of contracting a disease (Ives and Richeson, 2015). The fourth major use of antimicrobials in livestock production are to promote growth and performance of livestock focuses on decreasing the time it takes to grow animals to an appropriate weight for slaughter, improving the feed efficiency of these animals, and may result in more uniform animal weights when marketed or slaughtered (Sneeringer et al., 2015).

\section{Antimicrobial resistance}

Accurate diagnosis of BRD in calves is challenging and is based on subjective clinical observations by animal health technicians and rectal temperatures, which create limitations when diagnosing BRD (Ives and Richeson, 2015). Limitations associated with accurate BRD diagnosis contributes to the widespread use of metaphylactic 
antimicrobials for treatment of BRD (Ives and Richeson, 2015). Metaphylaxis is most often applied on arrival to calves that are determined to be at high risk for disease and when the ability to determine disease status of a group of calves or individual calf is absent (Ives and Richeson, 2015). The use of metaphylaxis has been shown to reduce both morbidity and mortality in calves upon feedlot arrival (Ives and Richeson, 2015).

Although the use of metaphylactic medication reduces morbidity and mortality in calves, along with improving growth performance, conflicts with public perception of judicious antimicrobial use have resulted in increases in concerns for microbial resistance (Benchaar et al., 2008; Calsamiglia et al., 2007). Concerns for microbial resistance in both humans and livestock have resulted in government regulations that limit the use of several specific antimicrobials in livestock production as growth promotants.

The European Union (EU), in 2003, banned the use of all but four antimicrobials as growth promotants in livestock feed and water (Greathead, 2003). In 2006, the EU further banned the use of all antimicrobials as growth promotants (Castillejos et al., 2007). The U.S. Food and Drug Administration (FDA) implemented the Veterinary Feed Directive (VFD) in 2015 to regulate how antibiotics that are medically important for human health are legally used within animal agriculture. The VFD requires producers to obtain authorization from a licensed veterinarian to administer antimicrobials to livestock (FDA, 2020). Changes in legislation that restrict use of antimicrobials for livestock has led to increased interest in alternative feed additives, such as essential oils, that may provide health and animal performance benefits. 


\section{History of essential oils}

Plants produce secondary metabolites as a natural protection and defense against drought, insects, microbes, and stress (Wallace, 2004). Secondary metabolites are byproducts of primary plant metabolism. They have been termed anti-nutritional or nonnutritional factors, as they were thought to not contribute any nutritional value to livestock (Acamovic and Brooker, 2005; Greathead, 2003; Reddy et al., 2020). Some secondary metabolites can be toxic to animals, but others may enhance health and growth performance (Wallace, 2004).

Secondary metabolites, such as essential oils (EO) have been extracted and used for medicinal purposes for centuries. The first use of plant-based medicines dates to 2600 BCE in Mesopotamia (Newman et al., 2000). Societies located in Africa, Asia, and India began using plants for medicinal properties between 1500 and $1000 \mathrm{BC}$ and ancient Greeks substantially contributed to the development of plant-based medicines (Newman et al., 2000). The first descriptions of the antimicrobial properties of plants used for medicinal properties appeared in the early $20^{\text {th }}$ century (Hoffman and Evans, 1911; Calsamiglia et al., 2007). Essential oils were widely used as "natural medicines" until the development of synthetic drugs occurred in the twentieth century (Patra, 2012). Controversy over the use of antimicrobials administered to livestock as growth promotants caused a resurgence of interest in EO (Patra, 2012).

Essential oils have antimicrobial properties that can benefit animal health and performance through modified ruminal fermentation (Hart et al., 2008). They are volatile and aromatic compounds, derived from the quinta essentia, or components responsible 
for the essence and fragrance of plants (Hart et al., 2008). Essential oils can be extracted through steam distillation or solvent extraction (Greathead, 2003) of a wide variety of plants. Concentrations of EO are variable between and within plants, which can be influenced by plant maturity, plant health, moisture, temperature, and light (Hart et al., 2008).

Structurally, EO are classified as alcohol, ester, or aldehyde derivatives and are divided into 2 major chemical groups, terpenes and phenylpropenes, (Greathead, 2003; Hart et al., 2008). Both terpenes and phenylpropenes consist of non-nitrogenous hydrocarbons (Acamovic and Brooker, 2005; Hart et al., 2008) and are derived from various metabolic pathways (Calsamiglia et al., 2007).

Essential oils with a terpene structure are the most abundant EO. They are characterized based on a basic five carbon isoprene unit structure (Calsamiglia et al., 2007). Terpenes are derived from acetyl-CoA via the mevalonate and deoxyxylulose pathways (Edwards and Gratehouse, 1999; Hart et al., 2008). Through these pathways, glucose is converted into 3 acetyl-CoA. The acetyl-CoA is then converted into isopentenyl pyrophosphate, and then converted into the terpenes (Calsamiglia et al., 2007). Capsaicin, thymol, and carvacrol are examples of EO with a terpene structure.

Phenylpropenes are less abundant than terpenes and consist of a three-carbon chain bound to an aromatic 6 carbon ring (Calsamiglia et al., 2007). These are derived from phenylalanine via the Shikimate pathway (Edwards and Gratehouse, 1999; Hart et al., 2008). Through this pathway pentose is converted into shikimic acid with the addition of phosphoenolpyruvate. Phenylalanine and tyrosine are produced, and these form 
cinnamic and coumaric acid. These 2 products are then converted into the phenylpropenes. Essential oils with a phenylpropene structure include anethol, eugenol, and cinnamaldehyde (Calsamiglia et al., 2007).

\section{Mode of action}

Essential oils exert varying effects on animal health and performance through antimicrobial properties, but their exact mode of action is unclear. The primary mode of action of EO is thought to be through induction of cell death by activating apoptosis, cell cycle arrest, and loss of function of essential organelles within a cell (Sharifi-Rad et al., 2017). These effects are due to interactions and disruption of cell membranes due to the lipophilic properties of the EO (Sharifi-Rad et al., 2017).

Antimicrobial activity of EO has been demonstrated on both gram-positive and gram-negative bacteria (Benchaar et al., 2008). Although, it appears that gram-positive bacteria are more susceptible to EO than gram-negative bacteria (Benchaar et al., 2008; Burt, 2004), possibly due to the outer membrane that surrounds the cell wall of gramnegative bacteria providing a physical barrier to cell entry by EO (Benchaar et al., 2008).

Mode of action in gram-positive bacteria has been thought to occur through interactions with the cell membrane (Calsamiglia et al., 2007) due to the hydrophobic nature of the cyclic hydrocarbons that make up EO (Calsamiglia et al., 2007). The hydrophobic nature of the EO give them a high affinity for lipids found in bacterial cell membranes (Benchaar et al., 2008). They can accumulate in the lipid bilayer of cells (Sikkema et al., 1994; Ultee et al., 1999) and then cause conformational changes in cell membranes resulting in loss of membrane stability (Calsamiglia et al., 2007; Griffin et 
al., 1999). This loss of membrane stability causes a decrease in the ion gradient in the cell wall. This results in ATP being used to facilitate transport of ions across cell membranes via ion pumps, thus decreasing growth of bacteria (Bittner, 2016). This mode of action is similar to the mode of action of ionophores. Ionophores are carboxylic polyether antibiotics that transport cations into cells (Sewell, 1993) and thus disrupt the ion gradient to inhibit the functionality and reproduction of microbes (Felix, 2017). The disruption of the ion gradient thus alters the metabolism of gram-positive bacteria and protozoa in the rumen (Hersom and Thrift, 2012).

Though EO appear to affect gram-positive bacteria to a greater extent, gramnegative bacteria do not seem to be completely resistant to EO. Essential oils have the potential to permeate the outer membrane of gram-negative bacteria through interactions with water molecules and formation of hydrogen bridges due to their low molecular weight (Calsamiglia et al., 2007). They also have the capacity to disintegrate the outer membrane of gram-negative bacteria through release of lipopolysaccharides and increases in the permeability of the cytoplasmic membrane (Calsamiglia et al., 2007; Helander et al., 1998).

\section{Ruminal fermentation modification}

Ruminants possess a symbiotic relationship with microorganisms found within their rumen. The animal provides a desirable environment for microorganisms to exist that is aqueous, maintains a constant temperature and $\mathrm{pH}$ range, provides a constant supply of substrate (i.e., feed), and allows for continuous mixing of substrates. Feed consumed by ruminants comes into contact with this diverse group of anaerobic 
microorganisms that work to degrade and digest substrates. These microorganisms in turn produce end products of fermentation that include microbial cells, volatile fatty acids (VFA), methane, ammonia, carbon dioxide, and hydrogen gas. Volatile fatty acids are utilized by the host and supply a large portion of the ruminant's energy supply. Acetate, propionate, and butyrate are 3 major VFA produced in the rumen; however, some of these end products (methane, ammonia, carbon dioxide) are losses of protein and energy. These losses can reduce animal performance and ruminal efficiency (Calsamiglia et al., 2007). Throughout the years there has been interest in improving the efficiency of energy and protein utilization in the rumen through the use of feed additives (Calsamiglia et al., 2007). Recent interest in utilizing EO has been based on the thought that they have the ability to manipulate rumen fermentation by affecting microbes, which may improve ruminal efficiency and animal production.

Effects of EO on ruminal fermentation have been variable and contradictory in the literature. These variable effects are potentially due to physiological age of the animals, diet type, specific EO, EO dose, rumen $\mathrm{pH}$, and type of experiment (in vitro vs. in vivo vs. in situ).

Westerhold (2013) evaluated the effects of diallyl sulfide and cinnamaldehyde (Next Enhance, Novus International, Inc., St. Charles, MO), which are EO derived from garlic and cinnamon, on rumen fermentation characteristics in vivo. Five Hereford steers fitted with rumen and duodenal cannulas were assigned to 1 of 5 treatments of a mixture of diallyl sulfide and cinnamaldehyde at $0,0.008,0.02,0.03$, and $0.030 \mathrm{~g} / \mathrm{kg}$ of diet DM. All steers were offered a basal diet of 70.5\% ground corn, $15.1 \%$ dried distiller's grains, 8.0\% alfalfa hay, and $3.4 \%$ AminoPlus $^{\circledR}$, and $2.9 \%$ vitamins and minerals (DM basis). 
Total VFA and acetate production decreased quadratically as inclusion of diallyl sulfide and cinnamaldehyde increased in the diet. Total VFA production decreased approximately $12.4 \%$ when $0.015 \mathrm{~g} / \mathrm{kg}$ of a mixture diallyl sulfide and cinnamaldehyde was added to the diet compared with control, but only a $1.3 \%$ difference was in total VFA production was observed between control and inclusion of $0.03 \mathrm{~g} / \mathrm{kg}$ of a mixture diallyl sulfide and cinnamaldehyde. A $14.5 \%$ decrease in acetate production was also observed when $0.015 \mathrm{~g} / \mathrm{kg}$ of a mixture diallyl sulfide and cinnamaldehyde was added to the diet when compared with control, though, only a $1.7 \%$ difference in acetate production was observed between control and inclusion of $0.03 \mathrm{~g} / \mathrm{kg}$ of a mixture diallyl sulfide and cinnamaldehyde. However, rumen $\mathrm{pH}$, ammonia, propionate, and butyrate were not affected by inclusion of a mixture diallyl sulfide and cinnamaldehyde.

Newbold and others (2004) investigated the effects of a blend of thymol, guaiacol, and limonene (Crina Ruminants, AKZO Nobel, CRINA S.A., Gland, Switzerland) on rumen fermentation in sheep. Four ruminally cannulated sheep were fed a $40 \%$ concentrate, $60 \%$ grass silage-based diet. Concentrate was a combination of $73 \%$ barley grain, $12.5 \%$ rapeseed meal, $5.0 \%$ soybean meal, $8.0 \%$ molasses, and $1.5 \%$ mineral and vitamin supplement. The sheep were offered either EO or no EO. The addition of EO did not affect ruminal $\mathrm{pH}$, ammonia concentration, or individual VFA proportions, but sheep offered EO tended to have greater increases in total VFA concentration from 2 to 6 hours post-feeding, which was associated with a small numerical decrease in the proportion of acetate.

Yang et al. (2010a) evaluated the effect of cinnamaldehyde on rumen fermentation in beef heifers. Four ruminally and duodenally cannulated beef heifers were 
offered a diet of $15 \%$ barley silage, $80 \%$ dry-rolled barley grain, and $5 \%$ supplement. The heifers were assigned to 1 of 4 treatments of increasing doses of cinnamaldehyde at 0 , 0.4, $0.8,0.16 \mathrm{~g} / \mathrm{hd} / \mathrm{d}$. Yang et al (2010a) observed no differences in total VFA concentrations or proportions of acetate, propionate, and butyrate when beef heifers were supplemented with cinnamaldehyde. There was also no effect of increasing dose of cinnamaldehyde on ruminal $\mathrm{pH}$, ammonia concentrations, or relative concentrations of acetate and propionate.

Tager and Krause (2011) used 8 ruminally cannulated Holstein cows to evaluate the effects of a mixture of cinnamaldehyde, eugenol (XT 6965, Pancosma S. A., Bellegarde-sur-Valserine, France), and capsicum (XT 6933, Pancosma S. A., Bellegardesur-Valserine, France) on rumen fermentation. Cows were offered a total mixed ration (TMR) of $34.4 \%$ corn silage, $32.0 \%$ ground corn grain, $11.0 \%$ soybean hulls, $7.3 \%$ chopped alfalfa hay, $2.9 \%$ hydrolyzed feather meal, and $2.0 \%$ supplement. Treatments of $0.5 \mathrm{~g} / \mathrm{cow} / \mathrm{day}$ of a mixture of cinnamaldehyde and eugenol, $10 \mathrm{~g} / \mathrm{cow} /$ day of a mixture of cinnamaldehyde and eugenol, $0.25 \mathrm{~g} / \mathrm{cow} /$ day of capsicum, or no EO. Ammonia, total VFA, and individual VFA concentrations were not affected by EO treatments. Rumen $\mathrm{pH}$ was also not affected by addition of EO.

Yang et al. (2010c) evaluated the effects of increasing eugenol supplementation on rumen fermentation in 4 ruminally and duodenally cannulated beef heifers. Heifers were assigned to 1 of 4 treatments of $0,0.4,0.8,0.16 \mathrm{~g} /$ heifer/day of eugenol. Heifers were offered a TMR of $15 \%$ barley silage, $80 \%$ dry-rolled barley grain, and $5 \%$ supplement. No differences in rumen $\mathrm{pH}$, total VFA, propionate, or butyrate concentrations were observed between treatments; however, concentration of acetate 
decreased linearly as eugenol intake increased. Also, proportion amounts of propionate tended to increase as eugenol intake increased, which resulted in a decrease in the relative concentrations of acetate and propionate.

Anassori et al. (2011) evaluated the effects of garlic as a potential alternative for monensin and measured rumen fermentation characteristics in 4 ruminally cannulated sheep across 3 experiments. Sheep were offered a basal diet of $38.1 \%$ alfalfa hay, $39.7 \%$ corn silage, $8.5 \%$ soybean meal, $11.0 \%$ barley grain, and $2.7 \%$ wheat bran (DM basis). For the first experiment, sheep were assigned to 1 of 4 treatments that consisted of control (no additives), $75 \mathrm{~g} / \mathrm{kg}$ DM raw garlic bulb, $0.500 \mathrm{~g} / \mathrm{kg}$ DM garlic oil, or 0.033 g/kg DM monensin (Anassori et al., 2011). Ammonia concentrations decreased after 14 and 21 days when sheep were supplemented with $0.033 \mathrm{~g} / \mathrm{kg}$ DM monensin or $0.5 \mathrm{~g} / \mathrm{kg}$ DM garlic oil when compared to control but did not decrease when supplemented with 75 $\mathrm{g} / \mathrm{kg}$ DM raw garlic bulb. All treatments decreased acetate concentrations after 14 and 21 days in comparison to control, though monensin exhibited the greatest effect, with acetate concentrations $9 \%$ smaller than control. Propionate concentrations increased with the addition of garlic or monensin when compared with control, though again, monensin exhibited the greatest effect, with propionate concentrations $9 \%$ greater than control. Addition of $0.5 \mathrm{~g} / \mathrm{kg}$ garlic oil resulted in greater butyrate concentrations compared with control, $75 \mathrm{~g} / \mathrm{kg}$ DM raw garlic bulb, or $0.033 \mathrm{~g} / \mathrm{kg}$ DM monensin after 14 and 21 days.

Treatments for the second experiment were similar to the first experiment, but concentration of raw garlic bulb and garlic oil increased to $100 \mathrm{~g} / \mathrm{kg} \mathrm{DM}$ and $0.75 \mathrm{~g} / \mathrm{kg}$ garlic oil, respectively, along with control (no additives) and $0.033 \mathrm{~g} / \mathrm{kg}$ DM monensin (Anassori et al., 2011). Within experiment 2, ammonia concentrations decreased after 14 
when sheep were supplemented with $100 \mathrm{~g} / \mathrm{kg}$ DM raw garlic bulb, $0.75 \mathrm{~g} / \mathrm{kg}$ DM garlic oil, or $0.033 \mathrm{~g} / \mathrm{kg}$ DM monensin when compared with control, with monensin exhibiting the greatest decrease. After 21 days, ammonia concentrations decreased when sheep were supplemented with $750 \mathrm{mg} / \mathrm{kg}$ garlic oil or monensin when compared with control, with monensin again exhibiting the greatest decrease. Acetate concentrations decreased after 14 and 21 days when sheep were supplemented with garlic or monensin, and propionate proportions increased after 14 and 21 days when sheep were supplemented with garlic and monensin. Butyrate concentrations also increased after 14 and 21 days when sheep were supplemented with garlic and decreased when sheep were supplemented with monensin.

For the third experiment, treatments consisted of $75 \mathrm{~g} / \mathrm{kg}$ DM raw garlic bulb, 100 $\mathrm{g} / \mathrm{kg}$ DM raw garlic bulb, $0.5 \mathrm{~g} / \mathrm{kg}$ DM garlic oil, and $0.75 \mathrm{~g} / \mathrm{kg}$ DM garlic oil (Anassori et al., 2011). Ammonia concentrations decreased similarly to concentrations in experiments 1 and 2. After 14 days, ammonia concentrations decreased when sheep were supplemented with $100 \mathrm{~g} / \mathrm{kg}$ DM raw garlic bulb, $0.5 \mathrm{~g} / \mathrm{kg}$ DM garlic oil, or $0.75 \mathrm{~g} / \mathrm{kg}$ DM garlic oil and compared with the $75 \mathrm{~g} / \mathrm{kg}$ DM raw garlic bulb treatment. After 21 days, ammonia concentrations decreased when sheep were supplemented with garlic oil compared with raw garlic bulb. Acetate concentrations decreased after 21 days when sheep were supplemented with $0.75 \mathrm{~g} / \mathrm{kg}$ DM garlic oil compared with $75 \mathrm{~g} / \mathrm{kg}$ DM or $100 \mathrm{~g} / \mathrm{kg}$ DM raw garlic bulb. No differences in propionate concentrations were observed in experiment 3. Butyrate concentrations were greater when sheep were supplemented with $100 \mathrm{~g} / \mathrm{kg}$ DM raw garlic bulb, $0.5 \mathrm{~g} / \mathrm{kg}$ DM garlic oil, or $0.75 \mathrm{~g} / \mathrm{kg}$ DM garlic oil after 14 and 21 days when compared with the $75 \mathrm{~g} / \mathrm{kg}$ DM raw garlic bulb treatment. 
Throughout all 3 experiments, no differences were observed in rumen $\mathrm{pH}$ or total VFA concentrations between treatments. The lack of differences in rumen $\mathrm{pH}$ between treatments across all experiments was consistent with prior literature. Reductions in ammonia concentrations throughout the experiments suggests that adaptive mechanisms are in place when EO are supplemented or the lower levels of organosulfur compounds in garlic have an effect on ruminal fermentation (Anassori et al., 2011). Anassori et al. (2011) stated that garlic has the potential to improve rumen fermentation by increasing propionate production.

Effects of alfalfa extract, anise, capsicum, and a combination of cinnamaldehyde and eugenol on ruminal fermentation in Holstein heifers was studied by Cardozo et al. (2006). In this study, 4 Holstein heifers that were fitted with ruminal cannula were fed diets consisting of barley straw and concentrate. The concentrate consisted of $30 \%$ ground barley, $21 \%$ ground corn, $14 \%$ wheat bran, $15 \%$ soybean meal, $7 \%$ corn gluten feed, and $2.5 \%$ vitamin and mineral supplement, and $0.5 \%$ sodium bicarbonate on a DM basis. This study was separated into two different experiments, with the treatments in the first experiment consisting of control (no additives), $30 \mathrm{~g} / \mathrm{d}$ of alfalfa extract, $0.18 \mathrm{~g} / \mathrm{d}$ of cinnamaldehyde and $0.09 \mathrm{~g} / \mathrm{d}$ of eugenol, and a combination of the two treatments. The treatments for experiment 2 consisted of control (no additives), $2 \mathrm{~g} / \mathrm{d}$ anise extract, $1 \mathrm{~g} / \mathrm{d}$ capsicum extract, and a mixture of $0.6 \mathrm{~g} / \mathrm{d}$ cinnamaldehyde and $0.3 \mathrm{~g} / \mathrm{d}$ eugenol. Results from experiment 1 showed that there was no effect of feeding alfalfa extract or cinnamaldehyde and eugenol on rumen $\mathrm{pH}$, total VFA concentrations, or individual VFA proportions, except for an increase in the acetate to propionate ratio when heifers were supplemented with alfalfa extract. 
In experiment 2 , no effect of $\mathrm{EO}$ on rumen $\mathrm{pH}$ or total VFA concentrations was observed. Though, compared with control, proportion of acetate was decreased when heifers were supplemented with anise extract, capsicum extract, and a mixture of cinnamaldehyde and eugenol. Propionate proportions were greater when heifers were supplemented with anise extract and cinnamaldehyde and eugenol mixture when compared with control.

Effects of EO on rumen fermentation in prior literature are confounding. Diet type, EO type and dose, animal species and breed, and physiological age affect the response to EO supplementation. Rumen $\mathrm{pH}$ was not affected by EO regardless of dose, type, species and breed, physiological age, and diet type throughout previous literature discussed. Acetate concentrations and proportions were either decreased or had no change when EO were supplemented, and propionate was increased or not changed by intake of EO. Total VFA concentrations were variable also with increases, decreases, or no change, and similar results for ammonia. All of these changes in rumen fermentation impact the efficiency and digestion of feeds consumed by animals. Increases in propionate may increase efficiency of rumen fermentation through decreases in methane production, while increases in acetate and butyrate are associated with decreases in rumen fermentation efficiency and increases in methane production.

\section{Animal performance}

Effects of essential oils on performance measures have been variable in previous studies. The variable effects are potentially due to physiological age of the animals, species and breed of animals, diet type, specific EO, and amount of EO. 
Westerhold (2013) assessed the effects of a combination of EO extracted from garlic (diallyl disulfide) and cinnamaldehyde (Next Enhance, Novus International, Inc., St. Charles, MO) on growth performance and carcass characteristics in beef calves. This study utilized 98 crossbred steers that were fed a high concentrate diet with inclusions of $0,0.15,0.30$, or $0.60 \mathrm{~g} /$ head/day of EO There were no differences in DMI or BW between across treatments at any time point. There were also no differences in overall average daily gain (ADG) or feed efficiency across treatments during this experiment (Westerhold, 2013).

Benchaar and others (2007) studied the effects of a mixture of EO and silage source on rumen and milk characteristics. Four Holstein cows fitted with ruminal cannulas were assigned to treatments comprised of no supplementation $(\mathrm{CON})$ or supplementation with $0.750 \mathrm{~g} / \mathrm{d}$ of a mixture of EO (Crina Ruminants, CRINA, S.A., Gland, Switzerland) and alfalfa silage or corn silage as the forage source. No differences were reported in DMI when cows were supplemented with EO. Milk and 4\% FCM yields were not affected by the addition of EO to the diet. Milk lactose concentrations were greater for cows supplemented with EO compared to those fed no EO, though there were no effects of EO on concentrations of milk fat and protein, or yields of milk fat, protein, and lactose.

Tager and Krause (2011) evaluated the effects of feeding two commercially available EO products in 7 ruminally cannulated lactating Holstein dairy cows. Cows were fed a TMR consisting of $34.4 \%$ corn silage, $32 \%$ ground corn, $11 \%$ soybean hulls, $7.3 \%$ chopped alfalfa hay, $2.9 \%$ hydrolyzed feather meal, and $2.0 \%$ supplement. Essential oils were added at $0.5 \mathrm{~g}$ per cow per day cinnamaldehyde and eugenol (XT 
6965, Pancosma S. A., Bellegarde-sur-Valserine, France), $10 \mathrm{~g}$ per cow per day cinnamaldehyde and eugenol, and 0.25 g per cow per day capsicum (XT 6933, Pancosma S. A., Bellegarde-sur-Valserine, France). Dry matter intake, milk yield, and milk composition were not affected by addition of EO in the diet (Tager and Krause, 2011).

Yang et al. (2010b) supplemented increasing amounts $(0,0.4,0.8,1.6 \mathrm{~g} / \mathrm{head} / \mathrm{d})$ of cinnamaldehyde to 70 crossbred steers fed an $86 \%$ dry rolled barley grain diet. A tendency for a quadratic effect on DMI was observed during the experiment, with DMI being the greatest at the $0.4 \mathrm{~g} / \mathrm{head} /$ day cinnamaldehyde supplementation and least among cattle fed $1.6 \mathrm{~g} / \mathrm{head} /$ day cinnamaldehyde supplementation. Initial and final BW of steers were not affected by cinnamaldehyde supplementation and as a result ADG was also not different among treatments. Feed efficiency was also not affected by cinnamaldehyde supplementation.

Bittner (2016) studied the effects of EO, monensin, and tylosin on the performance of beef cattle in 3 separate experiments. The blend of EO used throughout these experiments was a blend of cinnamaldehyde and garlic oil (Next Enhance $300^{\circledR}$, Novus International, Inc.). In the first experiment, 40 pens of 10 crossbred beef steers were fed basal diets consisting of $53 \%$ dry rolled corn, $25 \%$ wet distiller's grain plus solubles, $16 \%$ corn silage, and $6 \%$ liquid supplement. The treatments consisted of no additives, EO $(0.3 \mathrm{~g} / \mathrm{hd} / \mathrm{d})$, monensin $(0.36 \mathrm{~g} / \mathrm{hd} / \mathrm{d})$ plus tylosin $(0.09 \mathrm{~g} / \mathrm{hd} / \mathrm{d})$ or EO $(0.3$ $\mathrm{g} / \mathrm{hd} / \mathrm{d})$ plus monensin $(0.36 \mathrm{~g} / \mathrm{hd} / \mathrm{d})$ and tylosin $(0.09 \mathrm{~g} / \mathrm{hd} / \mathrm{d})$. Bittner (2016) observed no differences in DMI, ADG, or G:F between steers fed EO or those fed control. 
The second experiment conducted by Bittner (2016) utilized 45 pens of 8 crossbred beef steers per pen that were fed a basal diet of $65 \%$ dry rolled corn, $25 \%$ wet distiller's grain plus solubles, 5\% wheat straw, and 5\% liquid supplement. Treatments for this experiment consisted of EO doses at $0,0.075,0.15,0.225$, and $0.3 \mathrm{~g} / \mathrm{hd} / \mathrm{d}$. Monensin and tylosin were also included in all treatments at $0.36 \mathrm{~g} / \mathrm{hd} / \mathrm{d}$ and $0.09 \mathrm{~g} / \mathrm{hd} / \mathrm{d}$. In this experiment, DMI decreased as EO intake increased linearly, with steers fed $0.225 \mathrm{~g} / \mathrm{hd} / \mathrm{d}$ EO having a $4.2 \%$ decrease and steers fed $0.3 \mathrm{~g} / \mathrm{hd} / \mathrm{d}$ EO having a $2.9 \%$ decrease in DMI compared to control. Differences in DMI did not, however, influence measures of ADG, and feed efficiency increased as intake of EO increased.

The third experiment conducted by Bittner (2016) consisted of 36 pens of 8 crossbred beef steers per pen fed a basal diet of $54 \%$ dry rolled corn, $25 \%$ wet distiller's grain plus solubles, $15 \%$ corn silage, and $6 \%$ liquid supplement. Treatments for this experiment were EO at $0,0.017,0.03$, and $0.05 \mathrm{~g} / \mathrm{kg}$ of diet DM. Monensin and tylosin were also included in all treatments at $0.36 \mathrm{~g} / \mathrm{hd} / \mathrm{d}$ and $0.09 \mathrm{~g} / \mathrm{hd} / \mathrm{d}$. Similar to the first experiment conducted by Bittner (2016), no differences in DMI, ADG, or G:F were observed as concentration of EO in the diet increased. Also, throughout all three of these experiments, no differences in carcass adjusted BW or live final BW were observed with inclusion of EO in the diets.

Bittner (2012) also evaluated the effects of EO and monensin plus tylosin on the performance of beef steers in a feedlot setting. 40 pens of steers with 10 steers per pen were fed a basal diet of 53\% dry-rolled corn, $25 \%$ wet distiller's grains, $16 \%$ corn silage, and 6\% supplement (DM basis) and assigned to 1 of 4 treatments: control (no additives), 
EO, monensin plus tylosin, and EO with monensin plus tylosin. There was no effect of EO on DMI, ADG, G:F, or BW.

A feedlot experiment with 50 pens of 9 to 10 crossbred yearling steers per pen was conducted by Meyer et al. (2009) to evaluate the effects 2 mixtures of EO, monensin, and tylosin on animal performance. Diets consisted of $66.0 \%$ high-moisture corn, $16.5 \%$ dry-rolled corn, $7.5 \%$ alfalfa hay, $5.0 \%$ liquid molasses, and 5.0\% dry supplement that consisted of urea, limestone, salt, trace minerals, tallow, vitamin premix, and supplement. Treatments consisted of no feed additives (control), a mixture of EO (thymol, eugenol, vanillin, guaiacol, limonene), an experimental mixture of EO (guaiacol, linalool, and $\alpha$ pinene), EO mixture plus tylosin, and monensin plus tylosin. Essential oil mixtures were targeted at $1.0 \mathrm{~g} /$ steer daily, tylosin targeted at $0.090 \mathrm{~g} /$ steer daily, and monensin targeted at $0.3 \mathrm{~g} /$ steer daily across treatments that included them. Meyer et al. (2009) observed that monensin plus tylosin had reduced DMI compared to the other 4 treatments, yet there were no differences in DMI between control and treatments containing EO. This reduction in DMI with monensin plus tylosin is typical when fed to steers (Potter et al., 1985). Feed efficiency was improved when steers were supplemented with the commercial EO mixture plus tylosin and when supplemented with monensin plus tylosin compared to control. The improved G:F for the EO mixture plus tylosin treatment which may have been partially due to improved G:F that is seen when tylosin is fed (Vogel and Laudert, 1994).

Variability in results from prior literature when animals were fed EO are due to multiple factors, which seem to include diet type, physiological age of the animals, rumen $\mathrm{pH}$, other feed additives used in conjunction with EO, EO type, and EO dose. 


\section{Essential oils and the immune system}

The immune system is a complex network that works to provide a powerful defense against disease and infection. The immune system consists of three major lines of defense. The first line of defense against pathogens such as viruses, bacteria, parasites, and fungi are the physical barriers of the skin and mucous membranes that line the digestive, respiratory, and reproductive tracts (Sompayrac, 2019). The innate immune system is the second line of defense that makes up the immune system. The innate immune system is the natural defense that is always present and ready to combat infections or disease (Abbas et al., 2018). The innate immune system components include complement proteins, phagocytes such as macrophages, neutrophils, and white blood cells, and natural killer cells. The third line of defense against disease and infection is the adaptive immune system. The adaptive immune system adapts to defend against specific diseases and infections through lymphocytes, production of antibodies, and memory cells (Sompayrac, 2019). Effects of EO on the immune system have not been characterized to a large extent and have also been variable in previous literature. Sources of variance across experiments has been attributed to differences in diet, EO source, EO amount, rumen $\mathrm{pH}$, species, and physiological age.

Yang et al (2010a) fed increasing amounts $(0,0.4,0.8,0.16 \mathrm{~g} / \mathrm{hd} / \mathrm{d})$ of cinnamaldehyde to 4 ruminally and duodenally cannulated beef heifers fed an $80 \%$ dryrolled barley grain diet to measure effects of cinnamaldehyde on immune status in growing heifers. No differences were observed in total white blood cell counts or lymphocytes. These authors (Yang et al., 2010a) concluded that cinnamaldehyde does not affect adaptive immune response. 
Yang et al. (2010c) evaluated the effect of increasing levels of eugenol supplementation on the blood metabolites and immune response in 4 ruminally and duodenally cannulated beef heifers. Heifers were assigned to 1 of 4 treatments of $0,0.4$, $0.8,0.16 \mathrm{~g} / \mathrm{heifer} /$ day of eugenol. Heifers were offered a TMR of $15 \%$ barley silage, $80 \%$ dry-rolled barley grain, and 5\% supplement. No differences in total white blood cell counts were observed between treatments, though, proportions of lymphocytes linearly increased as eugenol dose increased. This suggests that eugenol supplementation may enhance the activity of the adaptive immune system.

Hosoda et al. (2006) evaluated the effects of supplementation with 3 herbs (peppermint, clove, or lemongrass) on immunoglobulin $\mathrm{G}$ concentration in blood from 4 Holstein steers. The diet offered to the steers consisted of $50.0 \%$ timothy hay, $42.2 \%$ flaked corn, $8.0 \%$ soybean meal, $1.2 \%$ mineral premix, $0.3 \%$ vitamin premix, and $0.3 \%$ salt (DM basis). Treatments were no supplement (control), peppermint, clove, or lemongrass and were provided at $50 \mathrm{~g} / \mathrm{kg}$ of diet DM. Immunoglobulin $\mathrm{G}$ concentrations were reduced when steers were supplemented with the 3 herbs compared to steers fed control, indicating that feeding herbs to cattle may affect the adaptive immune system and antibody activity. The previous study and the current study conflict in their results, though both studies ultimately evaluated the effects of eugenol, the EO from cloves, on the adaptive immune system. The differences observed between the studies may be due to differences in diet type, because Hosoda et al. (2006) reported feeding steers a diet with a $50 \%$ forage to $50 \%$ concentrate ratio and Yang et al. (2010c) reported feeding steers a diet of $80 \%$ forage to $20 \%$ concentrate. 
El-Essawy et al. (2021) evaluated the effects of anise, clove, and thyme EOs on blood metabolites in lactating goats. Eight lactating goats were offered a diet of $40.0 \%$ berseem hay, $31.2 \%$ corn grain, $16.2 \%$ wheat bran, $10.2 \%$ soybean meal, and $2.4 \%$ supplement (DM basis). Goats were randomly assigned to 1 of 4 treatments consisted of no EO, anise oil, clove oil, or thyme oil. El-Essawy et al. (2021) reported that there were no differences in concentrations of globulins among treatments, suggesting there was no effect of $\mathrm{EO}$ on the adaptive immune system in goats.

Yang et al. (2007) studied the effects of feeding garlic and juniper berry EO on immune status in dairy cows. Four ruminally and duodenally cannulated lactating Holstein cows were fed a TMR consisting of $30.2 \%$ barley silage, $9.8 \%$ alfalfa hay, $47.5 \%$ steam-rolled barley grain, $3.36 \%$ corn gluten meal, $2.91 \%$ canola meal, $2.91 \%$ soybean meal, and 3.34\% supplement (DM basis). Cows were supplemented with 1 of 4 treatments of no EO, $0.33 \mathrm{~g} / \mathrm{cow} /$ day monensin, $5 \mathrm{~g} / \mathrm{cow} /$ day garlic oil, or $2 \mathrm{~g} / \mathrm{cow} /$ day juniper berry (DM basis). Yang et al. (2007) observed no differences in total white blood cell counts or proportions of lymphocytes between treatments, suggesting that feeding monensin or EO from garlic or juniper berry have no effect on the status of the adaptive immune system.

The effect of EO on the immune response in cattle are variable and may be dependent on multiple factors. Factors that influence response to EO has been suggested to include diet, rumen $\mathrm{pH}, \mathrm{EO}$ source, and $\mathrm{EO}$ amount. The conclusions from previous literature are variable, with increases or no changes in proportion of lymphocytes (Yang et al., 2010a; Yang et al., 2010c) suggesting that EO have no effect on the adaptive immune response or stimulate the adaptive immune system to have a greater response if 
disease or infection was present. The differences between these experiments may be due to the species type and diet type such that the beef heifers used in Yang et al. (2010a) and Yang et al. (2010c) were fed a high concentrate diet, lactating dairy cows in Yang et al. (2007) were fed a TMR, and the Holstein steers fed in Hosoda et al. (2006) were fed a TMR of $50 \%$ concentrate to $50 \%$ forage.

\section{Conclusion}

Antimicrobials are commonly used for treatment, prevention, and control of disease in beef production, along with enhancing growth and performance of animals. However, increased concern for microbial resistance that has led to reduced social acceptance and increases of government regulations of antimicrobials in livestock production.

Essential oils have antimicrobial properties that can manipulate rumen fermentation. Some have investigated the ability of essential oils to fight infectious disease and/or enhance the immune system of livestock. The effects of essential oils on rumen fermentation, animal performance, and immune system have been contradictory. Variation in responses are potentially due to physiological age of animals, species and breed of animals, diet type, EO source, EO amount, and rumen $\mathrm{pH}$. Essential oils may improve livestock health and productivity but more research on their effects in livestock is needed. 


\title{
CHAPTER 2. EFFECT OF ESSENTIAL OILS ON PERFORMANCE AND HEALTH OF GROWING CATTLE
}

\begin{abstract}
Concerns related to use of antimicrobials to improve ruminal efficiency and animal performance on increased rates of antimicrobial resistance has increased interest in feed additives such as essential oils. The objective of this study was to determine effects of a blend of essential oils (EO) added to a pelleted feed (MFA Cattle Charge, MFA Inc., Columbia, MO) on performance and immune system function of steers during a 56-day backgrounding phase. Eighty beef steers (initial BW $=267 \pm 2.6 \mathrm{~kg}$ ) were obtained from 3 different sources and assigned a risk classification based on distance traveled, previous health management, and incidence of disease. Steers were blocked by prior stress and initial body weight, then allocated to 1 of 2 treatments: a pelleted feed without EO (CONTROL; MFA Cattle Charge R-36) and a pelleted feed with EO (EO; MFA Cattle Charge R-36 with MFA Shield). Steers offered EO tended $(P=0.09)$ to have greater DMI than control. An interaction between treatment $\times$ day $\times$ source $(P<0.01)$ was observed for body weight (BW) measures. Specifically, measures of BW in steers offered EO and exposed to moderate amounts of stress tended $(P=0.06)$ to be greater than steers offered control and exposed to moderate amounts of stress after 14 and 42 days on feed. Also, after 56 days on feed, steers exposed to moderate stress and offered EO had greater $(P=0.02)$ measures of BW than steers exposed to moderate stress and offered control. A tendency for an interaction between treatment $\times$ day $\times$ source $(P=0.06)$ was observed for
\end{abstract}


ADG and feed efficiency. Steers offered EO and exposed to small stress had greater $(P=$ 0.02) measures of ADG after 56 days on feed when compared with steers offered control and exposed to small stress but did not differ at any other time point. Steers exposed to moderate stress and offered $\mathrm{EO}$ tended $(P=0.08)$ to have greater gains after 56 days on feed than steers offered control. Measures of feed efficiency were greater $(P=0.01)$ among steers offered EO and exposed to small amounts of stress after 56 days on feed when compared with steers offered control but were not different at any other time point or between moderate or large stressed steers offered EO or control. Addition of EO did not have an effect $(P=0.99)$ on concentrations of anti-egg albumin IgG, though an interaction between treatment $\times$ day $(P<0.01)$ was observed. Specifically, steers offered control had greater concentrations $(P=0.05)$ of anti-egg albumin $\operatorname{IgG}$ after 14 days on feed compared to steers offered EO, though concentrations did not differ $(P>0.32)$ between EO and control at any other time point. Under conditions of this experiment, inclusion of essential oils in a complete feed appeared to improve feed intake and weight gain in calves during the backgrounding phase.

\section{INTRODUCTION}

The "backgrounding" phase of modern cattle production commonly refers to when cattle are weaned and realimented to a greater plane of nutrition by feeding in confinement. Calves often arrive to backgrounding locations stressed from weaning and transportation. Additionally, cattle are normally comingled from various sources during the marketing process and upon arrival at the backgrounding facility, which introduces novel pathogens that can suppress immune function. Increases in morbidity can compromise animal performance, and antimicrobials are commonly used to ameliorate 
illness and improve animal. However, there has been an increased interest in the use of alternative substances such as essential oils (EO) due to concerns about antimicrobial resistance. These alternative substances serve as "natural" replacements for antimicrobial drugs.

Essential oils are plant secondary metabolites known for their characteristic odors. These oils have been reported to impart antimicrobial activities through interactions with cell membranes and disruption of ion gradients, which are similar to the actions of some currently approved antibiotics (e.g., ionophores; Bittner, 2016). Antimicrobial properties of EO may be useful to alter rumen fermentation (Benchaar et al., 2008) and to enhance animal performance and health (Calsamiglia et al., 2007). However, effects of EO have been inconsistent across experiments (Hart et al., 2008). Which may be due, in part, to different EO used across experiments, amounts fed, immune status of the cattle, or other innate differences across groups of cattle. Our objectives were to evaluate the performance and immune function of calves fed a completely pelleted feed with or without EO during backgrounding.

\section{MATERIALS AND METHODS}

\section{Animals and Experimental Design}

All animal husbandry protocols and experimental procedures that involved live animals were approved by the University of Missouri Animal Care and Use Committee (Protocol No. 9946). 
Eighty crossbred steers (initial BW $=267 \pm 2.6 \mathrm{~kg}$ ) with a lifetime history of management and health records were obtained from 3 separate experiment stations within the University of Missouri System. Immediately prior to the beginning of the experiment, steers were transported to the University of Missouri Beef Research and Teaching Farm, and risk classifications were assigned to each group of steers based on previous health management, transportation distance, and incidence of disease.

Steers assigned to the small stress group $(\mathrm{n}=16$; initial $\mathrm{BW}=256 \pm 6.0 \mathrm{~kg}$; age $=$ $278 \pm 5$ days) were sourced directly from the University of Missouri Beef Research and Teaching Farm (Columbia, MO; $38^{\circ} 53^{\prime} 26.08081^{\prime \prime}$ N, $92^{\circ} 15^{\prime} 51.5664$ ” W), and were not subjected to any form of shipping stress prior to the beginning of the experiment. Additionally, these steers were surgically castrated, treated with an anthelmintic (Dectomax, Zoetis, Kalamazoo, MI), vaccinated for infectious bovine rhinotracheitis, parainfluenza-3 virus, bovine respiratory syncytial virus, bovine virus diarrhea type I and II, Mannheimia haemolytica (Bovishield Gold One Shot, Zoetis, Kalamazoo, MI), Clostridium chauvoei, C. septicum, C. novyi, C. sordellii, and C. perfringens types C and D (Vision 7, Merck Animal Health, Madison, NJ) 94 days prior to the beginning of the experiment. Steers were weaned 53 days prior to the beginning of the study, provided a second vaccination against infectious bovine rhinotracheitis, parainfluenza-3 virus, bovine respiratory syncytial virus, bovine virus diarrhea type I and II, Mannheimia haemolytica (Bovishield Gold One Shot, Zoetis) and trained to eat from a concrete bunk.

Steers assigned to the moderate stress group $(\mathrm{n}=32$; initial $\mathrm{BW}=300 \pm 3.7 \mathrm{~kg}$; age $=308 \pm 3$ days) were obtained from the University of Missouri Wurdack Research Center (Cook Station, MO; 37 48’ 11.772” N, 91² 25’ 24.168” W). Steers were 
transported $181 \mathrm{~km} 9$ days prior to the beginning of the trial. Similar to steers classified as small stress, these steers were vaccinated for Mannheimia haemolytica, Pasteurella multocida (Pulmo-Guard PHM-1, Agri Laboratories, St. Joseph, MO), infectious bovine rhinotracheitis, bovine virus diarrhea, parainfluenza-3, bovine respiratory syncytial virus (ViraShield 6, Elanco US, Fort Dodge, IA; Pyramid 5, Boehringer Ingelheim, Duluth, GA), Clostridium chauvoei, C. septicum, C. novyi, C. sordellii, C. perfringens types C and D, and Moraxella bovis (Piliguard Pinkeye +7, Merck Animal Health, Madison, NJ) at 81 and 58 days prior to the beginning of the experiment and trained to eat from a feed bunk.

Steers assigned to the large stress group $(\mathrm{n}=32$; initial $\mathrm{BW}=247 \pm 3.8 \mathrm{~kg}$; age $=$ $294 \pm 3$ days) were obtained from the University of Missouri Southwest Research Center (Mt Vernon, MO; $\left.37^{\circ} 4^{\prime} 24.006 ” \mathrm{~N}, 93^{\circ} 52^{\prime} 43.8024 ” \mathrm{~W}\right)$ had a large prevalence (69\%; 22 out of 32) of infectious bovine keratoconjunctivitis (pink eye) upon arrival to the feedlot and were transported $313 \mathrm{~km} 10$ days prior to the beginning of the trail. Steers in this group were weaned, vaccinated against infectious bovine rhinotracheitis, parainfluenza-3 virus, bovine respiratory syncytial virus, bovine virus diarrhea Types I and II (Bovishield Gold 5, Zoetis, Kalamazoo, MI), Clostridium chauvoei, C. septicum, C. novyi, C. sordellii, C. perfringens types C and D, and Haemophilus somnus (Ultrabac 7/Somubac, Zoetis, Kalamazoo, MI), and treated with an anthelmintic (Valbazen, Zoetis, Kalamazoo, MI) at time of weaning 72 days prior to beginning of the trial.

Seven days prior to initiation of the feeding experiment, all steers were treated with an anthelmintic (Dectomax, Zoetis, Kalamazoo, MI) and vaccinated against infectious bovine rhinotracheitis, parainfluenxe-3 virus, bovine respiratory syncytial 
virus, bovine virus diarrhea type I and II (Bovishield Gold One Shot, Zoetis, Zoetis, Kalamazoo, MI ), Clostridium chauvoei, C. septicum, C. novyi Type B, C. haeomolyticum, C. tetani, and C. perfringens types C and D (Covexin 8, Merck Animal Health, Madison, NJ).

Upon arrival to the feedlot, steers were placed into 1 of 10 partially covered pens. Steers were fed brome hay ( $88 \%$ DM, 92\% OM, 63\% NDF, 40\% ADF, $8 \% \mathrm{CP})$ at 0700 and 1600 daily leading up to initiation of the experiment. Immediately prior to the beginning of the experiment, steers were weighed across 2 consecutive days and beginning body weight was calculated as the average body weight on $\mathrm{d}-1$ and 0 . Steers were stratified by body weight within source, and randomly assigned to 1 of 10 partially covered pens $(7.32 \mathrm{~m} \times 16.15 \mathrm{~m})$, with 8 steers per pen. Each pen was then fed a completely pelleted diet (Table 2.1), with monensin included at a rate of $39.6 \mathrm{mg} / \mathrm{kg}$ and either had cinnamaldehyde and capsicum essential oils added at 1\% of the diet (DM basis; EO) or no additions of essential oils (CONTROL).

Steers were fed once daily at 0700 , for a total of 56 days. Daily feed offered to each pen was equally delivered across 2 semi-autonomous feed monitoring systems designed to measure individual animal intake and feeding behavior (GrowSafe Systems, Alberta, Canada). On the first day of the trial, steers were fed at $3 \%$ of body weight on a DM basis, based on the average body weight of each pen. Orts were collected daily and weighed for dry matter intake calculations. Subsequently, feed was then offered at amounts calculated to provide $110 \%$ of the previous $24 \mathrm{~h}$ as fed intake. Measures of whole-body weight were then collected every 14 days and days 55 and 56 of the experiment. 


\section{Establishment of Humoral Immune Response}

Effects of EO on humoral immune response to chicken egg albumin were evaluated in 2 steers randomly selected from each pen using procedures outlined by Caroprese et al. (2009). On day 1, each steer received 2 subcutaneous injections of $2 \mathrm{mg}$ chicken egg albumin (OVA, Sigma Aldrich, St. Louis, MO) dissolved in $1 \mathrm{~mL}$ sterile saline solution and $1 \mathrm{~mL}$ of incomplete Freund's adjuvant. A subsequent injection of 2 mg chicken egg albumin dissolved in $1 \mathrm{~mL}$ sterile saline solution was given on day 14 when measures of total body weight were recorded. Subsequently, jugular blood (20-mL)

was collected into tubes containing $\mathrm{K}_{2}$ EDTA (Becton Dickinson, Franklin Lakes, NJ) and placed on ice prior to transport to the laboratory on $\mathrm{d} 1,14,28,42$ and 56 to allow for measures of anti-chicken egg albumin antibody titers in plasma. After transport to the laboratory, plasma was harvested by centrifugation $\left(1,200 \mathrm{x} \mathrm{g}\right.$ for $15 \mathrm{~min}$ at $\left.4^{\circ} \mathrm{C}\right)$ and frozen $\left(-80^{\circ} \mathrm{C}\right)$ until anti-chicken egg albumin IgG titers were measured via an enzymelinked immunosorbent assay (Caroprese et al., 2009).

\section{Chemical Analyses}

Feed samples were collected weekly and stored at $-4^{\circ} \mathrm{C}$ for chemical analyses. Ort samples were collected daily and stored at $-4^{\circ} \mathrm{C}$. Ort samples were then composited by week within pen.

Feed and ort samples were ground to pass through a 1-mm screen using a Wiley mill (No. 4, Thomas Scientific, Swedesboro, NJ) and analyzed for DM, OM, CP, NDF, $\mathrm{ADF}$, and ether extract. Dry matter content was measured by drying at $105^{\circ} \mathrm{C}$ for $16 \mathrm{~h}$, ash content was determined by incineration at $450^{\circ} \mathrm{C}$ for $16 \mathrm{~h}$, and $\mathrm{OM}$ content was 
calculated as the difference between 100 and the percent ash. Nitrogen was measured by combustion (method no. 990.03; AOAC, 2000) and CP was calculated as nitrogen $\times 6.25$. Ether extract was measured gravimetrically after extraction with diethyl ether (method no. 920.39; AOAC, 2000; Goldfisch Fat Extractor, Labconco, Kansas City, MO). Neutral detergent fiber and ADF were determined non-sequentially using an ANKOM Fiber Analyzer (ANKOM Technology Corp., Fairport, NY).

Amounts of anti-egg albumin IgG in plasma were measured in 96-well Ubottomed cell plates using methods similar to those described by Caroprese et al. (2009). Briefly, each well was coated with $100 \mu \mathrm{L}$ of antigen $(10 \mathrm{mg} \mathrm{OVA} / \mathrm{mL}$ phosphate buffered saline (PBS, Sigma Aldrich, St. Louis, MO)) and incubated at $4^{\circ} \mathrm{C}$ for 12 hours. Plasma was diluted in PBS via serial dilution to 5,000:1 by adding plasma (10 $\mu \mathrm{L})$ to 990 $\mu \mathrm{L}$ PBS, then vortexing the solution. Immediately following the vortex, 10 microliters of the diluted solution were added to $490 \mu \mathrm{L}$ of PBS to obtain $500 \mu \mathrm{L}$ total of solution. Plates were washed using a microplate washer (Thermo Fisher Scientific, Waltham, MA) with PBS + Tween solution ( $300 \mu \mathrm{L} /$ well/rinse, 1 rinse per wash cycle), then incubated with $1 \%$ skimmed milk (200 $\mu \mathrm{L}$ per well) at $37^{\circ} \mathrm{C}$ for 1 hour. After a second wash (300 $\mu \mathrm{L} /$ well/rinse, 1 rinse per wash cycle), diluted plasma (5,000:1 dilution in PBS; $(100 \mu \mathrm{L}$ per well)) was added and incubated at $37^{\circ} \mathrm{C}$ for 1 hour. Plates were washed for a third time (300 $\mu \mathrm{L} /$ well/rinse, 1 rinse per wash cycle). Anti-body binding was detected using horseradish peroxidase-conjugated rabbit anti-bovine IgG (Sigma Aldrich, St. Louis, MO) $(10 \mu \mathrm{L}$ horseradish peroxidase-conjugated rabbit anti-bovine IgG added to 199.99 mL PBS to obtain $2 \mathrm{~mL}$ solution, 20,000:1 dilution in PBS; $100 \mu \mathrm{L}$ per well) and incubated at $37^{\circ} \mathrm{C}$ for 1 hour. After a further washing $(300 \mu \mathrm{L} /$ well/rinse, 3 rinses per 
wash cycle), $50 \mu \mathrm{L}$ of tetramethyl benzidine substrate (TMBS, Sigma Aldrich, St. Louis, MO) was added to each well. Reactions were allowed to proceed for 10 minutes before a stop reagent for TMBS (Sigma Aldrich, St. Louis, MO) was added at $50 \mu \mathrm{L}$ per well. Optical density was measured at $450 \mathrm{~nm}$ and amounts of $\mathrm{IgG}$ were calculated using a standard curve determined from a scalar dilution of bovine IgG (Sigma Aldrich, St. Louis, MO).

\section{Statistical Analysis}

One animal was removed from the experiment on day 6 due to an abscess on its shoulder. The animal was replaced with an animal with the same prior stress and similar body weight (BW of replacement vs. BW of removed animal). Measures of feed intake, performance, and concentration of anti-egg albumin IgG in plasma were analyzed as repeated measures in a randomized complete block design using the Mixed procedures of SAS (version 9.4, SAS INC., Cary, NC). The model included the fixed effect of treatment, day, prior stress, and body weight block, and pen within each unique combination of prior stress and treatment were considered the random variable. Day was the repeated variable, steer within pen was the subject, and unstructured covariance provided the best fit (e.g., Akaike's information criterion). Least square means were calculated using the LSMeans option and when the $F$-statistic was significant $(P \leq 0.05)$ means were separated using a student's t-test. Calculated areas under the curve for measures of anti-egg albumin IgG in plasma were analyzed similarly to the repeated measures of feed intake, performance, and concentration of anti-egg albumin IgG in plasma; however, the model did not include the fixed effect of day. Orthogonal polynomials were used to analyze linear and quadratic trends across days. 


\section{RESULTS AND DISCUSSION}

Measures of DM, OM, CP, NDF, ADF, and ether extract are reported in Table 2.1. As expected, measures (mean \pm standard deviation) of DM ( $89.4 \pm 0.45), \mathrm{OM}(90.5$ $\pm 0.53), \mathrm{CP}(12.7 \pm 0.58), \mathrm{NDF}(43.2 \pm 2.36), \mathrm{ADF}(26.9 \pm 2.23)$ or ether extract $(3.5 \pm$ $0.37)$ did not differ $(P \geq 0 . \mathrm{XX})$ between control and EO. Essential oils did not impact chemical analyses of the diets, due to the small inclusion in the diet ( $1 \%$ of diet, DM basis).

Measures of DMI are reported in Table 2.2. Days on feed influenced DMI $(P \leq$ 0.01), such that DMI increased quadratically over the 56-day feeding period, with DMI being largest at day 42 . Measures of DMI tended to be $6 \%$ greater $(P=0.09)$ among steers fed EO $(7.2 \pm 0.13 \mathrm{~kg} \mathrm{DM})$ compared to control $(6.8 \pm 0.13 \mathrm{~kg} \mathrm{DM})$ throughout the experiment. Previous measures of effects of EO on DMI have been inconsistent.

Differences in diet type and composition may account for the differences in DMI between the current study and previous studies. In the present study, DMI tended to be greater when steers were fed EO, which is similar to steers offered a TMR of $75 \%$ grass silage and supplemented with $2 \mathrm{~g}$ /day or $4 \mathrm{~g}$ /day EO (Benchaar et al., 2006). In contrast to the current experiment, Tager and Krause (2011) observed no differences in DMI when steers were supplemented with mixtures of EO and fed a $34.4 \%$ corn silage, $32.0 \%$ ground corn, $11.0 \%$ soyhull, $7.3 \%$ alfalfa hay, $2.9 \%$ hydrolyzed feather meal, and $2.0 \%$ vitamins and minerals diet. Similarly, Meyer et al. (2009) observed no differences in DMI when steers were fed a $66 \%$ high-moisture corn diet and mixtures of EO alone or in combination with tylosin. Westerhold (2013) also observed no differences in DMI 
throughout a 118-day feeding period when steers were fed a corn-based diet and increasing amount of EO. Bittner (2016) observed no differences in DMI when steers were fed a 54\% dry-rolled corn, 25\% wet-distiller's grains, and 15\% corn silage-based diet and supplemented with EO.

Additionally, steers with moderate amounts of stress had greater DMI $(P=0.02)$ than steers that were exposed to small and large amounts of stress. Lightweight (e.g., $<$ $200 \mathrm{~kg}$ ) stressed cattle experience depressed feed intakes (Galyean et al., 1999), which is concurrent with the smaller intakes that were observed for steers exposed to large amounts of stress.

Body weight data is reported in Table 2.3. Effects of days on feed, diet and prior stress interacted $(P \leq 0.01)$ to influence measures of BW. Specifically, measures of BW were not different $(P \geq 0.10)$ among steers fed EO or control within steers exposed to small, moderate, or large amounts of stress immediately prior to this experiment or after 28 days on feed. Yet, steers fed EO and exposed to moderate amounts of stress prior to this experiment tended $(P=0.06)$ to have greater BW compared to moderately stressed steers fed control after 14 and 42 days on feed. After 56 days on feed, measures of BW were greater among moderately stressed steers fed EO compared to moderately stressed steers fed control $(P=0.02)$. But measures of BW among small and large stressed steers were not affected by $\operatorname{diet}(P \geq 0.10)$ at any point throughout the experiment, which contributed to similar overall measures of BW $(P=0.38)$ between EO or control, even though intake among steers fed EO tended $(P=0.06)$ to be greater in comparison to steers fed control. An effect of days on feed was observed for BW measures $(P<0.01)$, such that BW increased linearly over the 56-day feeding experiment. An interaction $(P<$ 
0.01 ) between treatment and days on feed was observed for BW measures. In particular, BW measures did not differ $(P \geq 0.26)$ between EO or control on days $0,14,28$, or 42 . Yet, measures of BW tended $(P=0.08)$ to be $3 \%$ greater in steers fed EO after 56 days on feed than steers fed control. Others (Benchaar et al., 2006; Westerhold, 2013) reported no differences in initial or final BW measures when steers were fed increasing amounts of EO. Ornaghi et al. (2017), however, observed greater final BW among steers fed EO compared to steers that were not fed EO.

Prior stress influenced BW measures $(P<0.01)$, with steers exposed to moderate amounts of stress having greater BW measures than steers exposed to small or large amounts of stress. Also, prior stress and days on feed interacted $(P<0.01)$ to influence BW measures. Specifically, steers exposed to moderate amounts of stress prior to the experiment had greater BW measures $(P<0.01)$ than steers exposed to small or large stress throughout the 56-day feeding period. Additionally, BW measures among steers exposed to small or large amounts of stress were not different $(P \geq 0.21)$ at any time point throughout the 56-day feeding period.

Measures of DMI as a percentage of BW are reported in Table 2.2. As expected, differences in DMI as a percentage of BW were observed for days on feed $(P<0.01)$, with DMI as a percentage of BW increasing quadratically over the 56-day feeding period. Specifically, DMI as a percentage of BW increased $(P<0.01) 0.4 \%$ from day 14 to 28 , and $0.3 \%$ from day 28 to 42 , but from day 42 to 56 , but DMI as a percentage of BW increased $(P<0.01) 0.1 \%$. Dry matter intake as a percent of BW were influenced $(P=$ 0.04) by prior stress, such that steers exposed to large amounts of stress prior to the feed period had greater $(P=0.02)$ DMI as a percentage of BW when compared to steers 
exposed to moderate amounts of stress. In addition, steers exposed to large stress tended $(P=0.06)$ to have greater DMI as a percentage of BW than steers exposed to small stress prior to the feeding period. Lofgreen (1983) reported that stressed calves consume greater quantities of a high-concentrate diet in comparison to non-stressed calves. An interaction $(P=0.02)$ between days on feed and prior stress was observed for DMI as a percentage of BW. Specifically, steers exposed to large stress had greater $(P \leq 0.02) \mathrm{DMI}$ as a percentage of BW throughout the 56-day feeding period when compared to steers exposed to moderate stress and had greater $(P \leq 0.03)$ DMI as a percentage of BW from day 28 through 56 when compared to steers exposed to small stress. This conflicts with data that found stressed cattle experience reduced feed intakes for 2 to 3 weeks after arrival (Galyean et al., 1999).

Measures of ADG are reported in Table 2.2. Similar to measures of BW, measures of ADG tended $(P=0.06)$ to be influenced by an interaction among days on feed, diet, and prior stress. Steers fed EO and exposed to small stress prior to the experiment had greater $(P=0.02)$ measures of ADG after 56 days on feed compared to steers fed control and exposed to small stress, but measures of ADG did not differ ( $P \geq$ 0.16) among EO or control in steers exposed to small stress at any other time. Similarly, measures of ADG tended $(P=0.08)$ to be greater in steers fed EO and exposed to moderate stress compared to control after 56 days on feed, but measures of ADG did not differ $(P \geq 0.18)$ between $\mathrm{EO}$ or control in steers exposed to moderate stress at any other point in the experiment. Yet, EO or control had no impact on measures of ADG among steers exposed to large stress at any time point in this experiment $(P \geq 0.45)$. Overall, measures of ADG were numerically $(P=0.16) 0.22 \mathrm{~kg} /$ day greater in steers fed $\mathrm{EO}$ 
compared to control. Benchaar et al. (2006) observed no differences in ADG when steers were supplemented with varying doses of EO. Yet, Ornaghi et al. (2017) observed greater measures of ADG when steers were fed varying levels and mixtures of EO when compared to steers that were not fed EO. Also, Westerhold (2013) and Bittner (2016) reported no differences in ADG when steers were supplemented with EO. These differences may be explained through diet type and EO type.

There tended $(P=0.07)$ to be an overall effect of prior stress on measures of $\mathrm{ADG}$, with steers exposed to moderate and large stress gaining approximately $0.5 \mathrm{~kg}$ more per day than steers exposed to small stress prior to the experiment. Measures of ADG decreased quadratically $(P<0.01)$ across the 56-day feeding period. Specifically, measures of ADG were smaller $(P \leq 0.01)$ after 28 days on feed compared to measures of ADG after 14 and 56 days on feed. Additionally, ADG was greater $(P<0.01)$ after 56 days on compared to measures of ADG after 42 days on feed. Measures of ADG after 42 days on feed tended $(P=0.06)$ to be smaller after 42 days on feed compared to measures of ADG after 14 days on feed. Furthermore, measures of ADG tended $(P=0.07)$ to be influenced by an interaction between days on feed and prior stress. Specifically, steers exposed to small amounts of stress had smaller measures of ADG $(P<0.01)$ after 28,42 , and 56 days on feed compared to steers exposed to moderate or large stress. Steers exposed to small stress also tended $(P \leq 0.04)$ to have smaller measures of ADG after 14 days on feed when compared with steers exposed to moderate or large stress. Also, measures of ADG were not different $(P \geq 0.61)$ between steers exposed to moderate or large amounts of stress at any time point throughout the 56-day feeding period. 
The lack of differences between steers exposed to moderate or large amounts of stress prior to the experiment is potentially explained through the theory of compensatory gain. Compensatory gain occurs when cattle grow at a faster than normal rate of gain after a period of nutrient restriction, and cattle that initially undergo compensatory gain may later grow at similar rates to animals that did not undergo nutrient restriction (Parish, 2010). Thus, steers exposed to large amounts of stress may have compensated for potential nutrient restriction prior to the initiation of the trial, the stress that was undergone during transportation, and the incidence of infectious bovine keratoconjunctivitis (pink eye) that was present.

Measures of feed efficiency (G:F) are reported in Table 2.2. Similar to measures of BW and rate of gain, measures of feed efficiency tended $(P=0.06)$ to be affected by an interaction among days on feed, diet, and prior stress. Specifically, measures of feed efficiency were not different $(P \geq 0.34)$ at any timepoint for steers with moderate or large amounts of stress fed EO or control. Yet, measures of feed efficiency were greater $(P=$ 0.01 ) among steers fed EO and exposed to small amounts of stress prior to the experiment compared to steers fed control after 56 days on feed. But measures of feed efficiency were not impacted $(P \geq 0.22)$ by EO or control at any other time point. However, overall feed efficiency tended $(P=0.08)$ to be less among steers exposed to small amounts of stress in comparison to steers exposed to moderate or large amounts of stress prior to the start of the experiment. Measures of feed efficiency were influenced by days on feed $(P<$ 0.01 ), specifically feed efficiency decreased quadratically across the 56-day feeding period. Also, measures of feed efficiency were influenced $(P=0.01)$ by an interaction between days on feed and prior stress. Specifically, steers exposed to small amounts of 
stress had smaller $(P \leq 0.01)$ measures of feed efficiency throughout the 56-day feeding period when compared to steers exposed to large amounts of stress. Steers exposed to small amounts of stress had smaller measures of feed efficiency after 28 days $(P=0.01)$ and 56 days $(P=0.04)$ on feed compared to steers exposed to moderate amounts of stress after 28 days on feed. Steers exposed to moderate amounts of stress tended $(P \geq 0.08)$ to have greater measures of feed efficiency after 14 and 42 days on feed when compared to steers exposed to small amounts of stress. Measures of feed efficiency tended to be greater $(P=0.06)$ in steers exposed to large amounts of stress after 42 days on feed when compared with steers exposed to moderate amounts of stress, but measures of feed efficiency were not different $(P \geq 0.25)$ between steers exposed to moderate or large amounts of stress at any other time point. Additionally, a tendency $(P=0.09)$ for an interaction between treatment and days on feed was observed, with greater measures of feed efficiency observed in steers fed EO compared to steers fed control after 56 days on feed, but no differences observed $(P \geq 0.23)$ between steers fed EO or control at any other time point. Benchaar et al. (2006) observed no differences in feed efficiency when steers were fed EO, but a quadratic effect of EO dose was observed, with steers supplemented with $2 \mathrm{~g} /$ day of EO had the greatest feed efficiency when compared to steers fed $4 \mathrm{~g} /$ day of EO or no EO. Similarly, Bittner (2016) also observed no differences in feed efficiency when steers were supplemented with EO. However, Meyer et al. (2009) observed a tendency for feed efficiency to improve when steers were fed EO.

Measures of anti-egg albumin IgG are reported in Table 2.4. Concentrations of anti-egg albumin $\operatorname{IgG}$ increased quadratically $(P \leq 0.01)$ over the 56 -day feeding period. Concentrations of anti-egg albumin $\operatorname{IgG}$ increased until day 28 , where the concentrations 
then began to decline. These results were similar to what is expected when the innate and adaptive immune systems are activated. Measures of anti-egg albumin IgG were influenced $(\mathrm{P}<0.01)$ by an interaction between treatment and days on feed. Specifically, steers fed control had greater $(P=0.05)$ concentrations of anti-egg albumin IgG after 14 days on feed compared to steers fed EO but circulating concentrations of anti-egg albumin IgG did not differ $(P \geq 0.32)$ at any other time. Furthermore, numerically greater $(P \geq 0.32)$ measures of anti-egg albumin IgG among steers fed EO after 28 and 42 days on feed compared to steers fed control resulted in similar $(P=0.99)$ measures of anti-egg albumin IgG across time (i.e., areas under the curve) between EO and control.

A tendency $(P=0.07)$ for an interaction between days on feed and prior stress was observed for concentrations of anti-egg albumin IgG. Concentrations of anti-egg albumin $\operatorname{IgG}$ tended $(P=0.06)$ to be greater in steers exposed to small amounts of stress after 56 days on feed compared to steers exposed to large amounts of stress, but no other differences $(P \geq 0.39)$ were observed at any other time point between steers exposed to small or large stress. Steers exposed to large amounts of stress had smaller $(P=0.04)$ concentrations of anti-egg albumin IgG after 14 days on feed compared to moderately stressed steers, and no other differences $(P \geq 0.11)$ were observed between moderate or large stressed steers at any other time point. Additionally, no differences $(P \geq 0.38)$ were observed in concentrations of anti-egg albumin IgG between steers exposed to small or moderate amounts of stress at any time point throughout the 56-day feeding period. These observations of a lack of response in humoral immune response to EO are similar to reports of effects of EO on adaptive immune response in cattle (Yang et al., 2007; Yang et al., 2010a; El-Essawy et al. 2021). However, Hosoda et al. (2006), observed decreases 
in concentration of $\operatorname{IgG}$ in steers supplemented with (peppermint, clove, or lemongrass). Alternatively, Yang et al. (2010b), observed an enhancement of the adaptive immune system among heifers fed eugenol. Incongruent reports on the impact of EO on immune response in cattle may be related to differences in diet type and type of EO used.

\section{CONCLUSION}

In conclusion, steers fed EO tended to have greater DMI, but no other differences were observed between treatments for $\mathrm{BW}, \mathrm{DMI}$ as a percentage of $\mathrm{BW}, \mathrm{ADG}$, feed efficiency, or anti-egg albumin IgG. Lack of treatment effects on measures of performance and health may be due to type of EO used, dose of EO, and physiological status of the cattle used in the experiment. Efficacy of EO supplementation may depend on cattle physiological status, specific EO, and dose of EO. 
Table 2.1. Chemical composition of complete feed with essential oils (EO) or without essential oils (control)

\begin{tabular}{lcc}
\hline & \multicolumn{2}{c}{ Treatment } \\
\cline { 2 - 3 } Chemical composition, \% & Control & EO \\
\hline Dry matter & 89.67 & 89.22 \\
Organic matter & 90.36 & 90.57 \\
Crude protein & 12.32 & 13.01 \\
Neutral detergent fiber & 45.26 & 41.21 \\
Acid detergent fiber & 28.87 & 24.95 \\
Ether extract & 3.58 & 3.33 \\
\hline
\end{tabular}


Table 2.2. Effect of essential oils (EO) or control on performance in backgrounding steers fed a complete feed.

\begin{tabular}{|c|c|c|c|c|c|c|c|c|c|c|}
\hline & \multicolumn{2}{|c|}{ Small stress } & \multicolumn{2}{|c|}{ Moderate stress } & \multicolumn{2}{|c|}{ Large stress } & \multirow[b]{2}{*}{ SEM } & \multicolumn{3}{|c|}{ P-values } \\
\hline & Control & $\mathrm{EO}$ & Control & $\mathrm{EO}$ & Control & $\mathrm{EO}$ & & Diet & Day & Source \\
\hline DMI, kg & & & & & & & 0.45 & 0.09 & $<0.01$ & 0.02 \\
\hline Day 1 to 14 & 4.24 & 4.82 & 4.80 & 5.29 & 4.48 & 4.58 & & & & \\
\hline Day 15 to 28 & 6.03 & 6.44 & 7.03 & 7.34 & 6.56 & 6.81 & & & & \\
\hline Day 29 to 42 & 7.25 & 7.93 & 8.83 & 9.34 & 8.32 & 8.60 & & & & \\
\hline Day 43 to 56 & 7.21 & 7.64 & 8.40 & 9.30 & 8.19 & 8.13 & & & & \\
\hline DMI, \% BW & & & & & & & 0.12 & 0.11 & $<0.01$ & 0.04 \\
\hline Day 1 to 14 & 1.66 & 1.97 & 1.64 & 1.75 & 1.85 & 1.84 & & & & \\
\hline Day 15 to 28 & 1.98 & 2.26 & 2.03 & 2.09 & 2.31 & 2.29 & & & & \\
\hline Day 29 to 42 & 2.23 & 2.56 & 2.38 & 2.44 & 2.71 & 2.69 & & & & \\
\hline Overall & 2.35 & 2.68 & 2.50 & 2.60 & 2.90 & 2.84 & & & & \\
\hline $\mathrm{ADG}, \mathrm{kg}$ & & & & & & & 0.36 & 0.16 & $<0.01$ & 0.07 \\
\hline Day 1 to 14 & 0.65 & 1.36 & 1.46 & 1.93 & 1.78 & 1.53 & & & & \\
\hline Day 1 to 28 & 0.63 & 1.01 & 1.80 & 1.53 & 1.35 & 1.51 & & & & \\
\hline Day 1 to 42 & 0.90 & 1.16 & 1.32 & 1.49 & 1.44 & 1.42 & & & & \\
\hline Overall & 0.91 & 1.30 & 1.38 & 1.58 & 1.45 & 1.42 & & & & \\
\hline Gain:feed & & & & & & & 0.07 & 0.35 & $<0.01$ & 0.08 \\
\hline Day 1 to 14 & 0.15 & 0.27 & 0.29 & 0.35 & 0.41 & 0.34 & & & & \\
\hline Day 1 to 28 & 0.12 & 0.18 & 0.23 & 0.23 & 0.25 & 0.27 & & & & \\
\hline Day 1 to 42 & 0.16 & 0.18 & 0.19 & 0.20 & 0.22 & 0.21 & & & & \\
\hline Overall & 0.15 & 0.19 & 0.19 & 0.20 & 0.21 & 0.20 & & & & \\
\hline
\end{tabular}

${ }^{1} \mathrm{DMI}$ as $\% \mathrm{BW}$, Day $\times$ Prior stress, $P=0.02$

${ }^{2}$ ADG, Day $\times$ Prior stress, $P=0.07$

${ }^{3}$ ADG, Treatment $\times$ Day $\times$ Prior stress, $P=0.06$

${ }^{4}$ Gain:feed, Day $\times$ Prior stress, $P<0.01$

${ }^{5}$ Gain:feed, Treatment $\times$ Day $\times$ Prior stress, $P=0.06$

${ }^{6}$ Gain:feed, Treatment $\times$ Day, $P=0.09$ 
Table 2.3. Effect of essential oils (EO) or control on body weight in backgrounding steers fed a complete feed.

\begin{tabular}{|c|c|c|c|c|c|c|c|c|c|c|}
\hline & \multicolumn{2}{|c|}{ Small stress } & \multicolumn{2}{|c|}{ Moderate stress } & \multicolumn{2}{|c|}{ Large stress } & \multirow[b]{2}{*}{ SEM } & \multicolumn{3}{|c|}{$P$-values } \\
\hline & Control & $\mathrm{EO}$ & Control & $\mathrm{EO}$ & Control & $\mathrm{EO}$ & & Diet & Day & Source \\
\hline $\mathrm{BW}, \mathrm{kg}$ & & & & & & & 9.31 & 0.38 & $<0.01$ & $<0.01$ \\
\hline Beginning & 264 & 247 & 295 & 305 & 243 & 251 & & & & \\
\hline Day 14 & 274 & 266 & 316 & 332 & 268 & 272 & & & & \\
\hline Day 28 & 282 & 275 & 333 & 348 & 281 & 293 & & & & \\
\hline Day 42 & 303 & 296 & 350 & 367 & 303 & 311 & & & & \\
\hline Final & 316 & 320 & 372 & 393 & 324 & 330 & & & & \\
\hline
\end{tabular}


Table 2.4. Effect of essential oils (EO) or control on IgG Concentration and Area Under the Curve in backgrounding steers fed a complete feed.

\begin{tabular}{|c|c|c|c|c|c|c|c|c|c|c|}
\hline & \multicolumn{2}{|c|}{ Small stress } & \multicolumn{2}{|c|}{ Moderate stress } & \multicolumn{2}{|c|}{ Large stress } & \multirow[b]{2}{*}{ SEM } & \multicolumn{3}{|c|}{$P$-values } \\
\hline & Control & $\mathrm{EO}$ & Control & $\mathrm{EO}$ & Control & $\mathrm{EO}$ & & Diet & Day & Source \\
\hline IgG & & & & & & & 1.71 & 0.99 & $<0.01$ & 0.33 \\
\hline Day 1 & 2.39 & 2.40 & 2.29 & 2.25 & 2.21 & 2.35 & & & & \\
\hline Day 14 & 7.05 & 5.28 & 7.74 & 6.74 & 6.50 & 3.77 & & & & \\
\hline Day 28 & 6.26 & 9.45 & 8.49 & 9.67 & 7.91 & 6.77 & & & & \\
\hline Day 42 & 6.26 & 8.00 & 6.91 & 7.18 & 6.38 & 6.09 & & & & \\
\hline Day 56 & 6.45 & 6.41 & 5.56 & 6.35 & 5.32 & 4.32 & & & & \\
\hline Area under the curve & 364.72 & 409.53 & 373.94 & 394.76 & 339.48 & 276.49 & 74.85 & 0.99 & & 0.37 \\
\hline
\end{tabular}

${ }^{1}$ Treatment $\times$ Day, $P<0.01$
${ }^{1}$ Day $\times$ Prior stress, $P=0.07$ 


\title{
CHAPTER 3. EFFECTS OF ESSENTIAL OILS ON FEEDING BEHAVIOR OF GROWING CATTLE
}

\begin{abstract}
Concerns that use of antimicrobials in beef production contributes to antimicrobial resistance has increased interest in essential oils (EO) as replacement for antibiotics fed to cattle. Eighty beef steers of different prior stress classifications were used in a 56-day feeding experiment to evaluate effects of a blend of EO in completely pelleted feed (MFA Cattle Charge, MFA Inc., Columbia, MO) on feeding behavior using a semi-autonomous feed intake monitoring systems (GrowSafe Systems, Alberta, Canada). Intermeal intervals across all cattle were 28 minutes and 40 seconds. Dry matter intake was not affected by addition of EO $(P=0.11)$, though an effect of day $(P<0.01)$ was observed. Feeding rate was influenced by a treatment by day interaction $(P=0.02)$, with steers consuming EO having a greater $(P \leq 0.03)$ feeding rate on days 11 and 44 and tended $(P=0.09)$ to have a greater feeding rate on day 8 when compared to steers offered control. Number of meals tended $(P=0.09)$ to be affected by prior stress, with steers exposed to large stress having a greater number of meals per day than steers exposed to small stress. Meal duration was influenced $(P=0.04)$ by prior stress. Steers exposed to moderate stress had $(P=0.02)$ a longer meal duration than steers exposed to large stress and tended $(P=0.08)$ to have a longer meal duration than steers exposed to small stress.
\end{abstract}




\section{INTRODUCTION}

Essential oils (EO) are plant secondary metabolites known for their characteristic odors. Concerns and changes in policy related to use of antimicrobial drugs in livestock feed has led to increased interest in using alternative feed additives such as EO. Essential oils are thought to alter rumen fermentation patterns (Hart et al., 2008; Tager and Krause, 2011) and feeding behavior in cattle. Rodriguez-Prado et al. (2008) reported increased time spent eating and shorter, more frequent meals in beef heifers supplemented with a $0.5 \mathrm{~g}$ capsicum per day. A blend of cinnamaldehyde and eugenol reduced meal length without affecting rumen fermentation (Tager and Krause, 2011).

Various methods have been used to measure feeding behavior in cattle. Wangsness et al. (1976) defined a meal as at least 1 minute of eating activity after at least 20 minutes without eating activity. Tager and Krause (2011) visually monitored feeding behavior for a 24-hour period within each sampling period. Eating and rumination activities were recorded every 5 minutes and each activity was assumed to persist for the entire 5-minute interval (Tager and Krause, 2011). Automated feed measurement systems allow for more precise feeding behavior measurements. These systems allow for continuous, noninvasive monitoring of feeding behavior by individual animals utilizing radio frequency identification (Wolfger et al., 2015). GrowSafe systems (GrowSafe System Ltd., Airdrie, Alberta, Canada) have load cells that measure feed bunk weight before and after an animal visit.

Conceptually, daily feed intake is the result of number of meals and the size of each meal. The definition of a meal is dependent on methods used. Some meal 
criteria are selected arbitrarily. Tager and Krause (2011) defined a meal as at least one observation of eating activity occurring after at least 20 min without eating activity. Tolkamp et al. (2000) analyzed over 200,000 records of visits to feeders by cows and used log-normal models to estimate individual meal criteria. After individual meal criteria were determined, visits were grouped into meals and then the effects of treatments were analyzed.

The objectives of this experiment were to determine the impact of EO on feeding behavior in growing beef cattle, using GrowSafe intake monitoring systems.

\section{MATERIALS AND METHODS}

\section{Animals and Experimental Design}

All animal husbandry protocols and experimental procedures that involved live animals were approved by the University of Missouri Animal Care and Use Committee (Protocol No. 9946).

Eighty crossbred steers (initial BW $=267 \pm 2.6 \mathrm{~kg}$ ) with a lifetime history management and health records were obtained from 3 separate experiment stations within the University of Missouri System. Immediately prior to the beginning of the experiment, steers were transported to the University of Missouri Beef Research and Teaching Farm, and risk classifications were assigned to each group of steers based on previous health management, transportation distance, and incidence of disease.

Steers assigned to the small stress group $(\mathrm{n}=16$; initial $\mathrm{BW}=256 \pm 6.0 \mathrm{~kg}$; age $=$ $278 \pm 5$ days) were sourced directly from the University of Missouri Beef Research and 
Teaching Farm (Columbia, MO; 38 53' 26.08081" N, 92 ${ }^{\circ} 15^{\prime}$ 51.5664” W), and were not subjected to any form of shipping stress prior to the beginning of the experiment. Additionally, these steers were surgically castrated, treated with an anthelmintic (Dectomax, Zoetis, Kalamazoo, MI), vaccinated for infectious bovine rhinotracheitis, parainfluenza-3 virus, bovine respiratory syncytial virus, bovine virus diarrhea type I and II, Mannheimia haemolytica (Bovishield Gold One Shot, Zoetis, Kalamazoo, MI), Clostridium chauvoei, C. septicum, C. novyi, C. sordellii, and C. perfringens types C and D (Vision 7, Merck Animal Health, Madison, NJ) 94 days prior to the beginning of the experiment. Steers were weaned 53 days prior to the beginning of the study, provided a second vaccination against infectious bovine rhinotracheitis, parainfluenza-3 virus, bovine respiratory syncytial virus, bovine virus diarrhea type I and II, Mannheimia haemolytica (Bovishield Gold One Shot, Zoetis) and trained to eat from a concrete bunk.

Steers assigned to the moderate stress group $(\mathrm{n}=32$; initial $\mathrm{BW}=300 \pm 3.7 \mathrm{~kg}$; age $=308 \pm 3$ days) were obtained from the University of Missouri Wurdack Research Center (Cook Station, MO; $37^{\circ} 48^{\prime} 11.772 ”$ N, $91^{\circ} 25^{\prime} 24.168^{\prime}$ W). Steers were transported $181 \mathrm{~km} 9$ days prior to the beginning of the trial. Similar to steers classified as small stress, these steers were vaccinated for Mannheimia haemolytica, Pasteurella multocida (Pulmo-Guard PHM-1, Agri Laboratories, St. Joseph, MO), infectious bovine rhinotracheitis, bovine virus diarrhea, parainfluenza-3, bovine respiratory syncytial virus (ViraShield 6, Elanco US, Fort Dodge, IA; Pyramid 5, Boehringer Ingelheim, Duluth, GA), Clostridium chauvoei, C. septicum, C. novyi, C. sordellii, C. perfringens types C and D, and Moraxella bovis (Piliguard Pinkeye +7, Merck Animal Health, Madison, NJ) 
at 81 and 58 days prior to the beginning of the experiment and trained to eat from a feed bunk.

Steers assigned to the large stress group $(n=32$; initial $\mathrm{BW}=247 \pm 3.8 \mathrm{~kg}$; age $=$ $294 \pm 3$ days) were obtained from the University of Missouri Southwest Research Center (Mt Vernon, MO; $37^{\circ} 4^{\prime} 24.006$ " N, $\left.93^{\circ} 52^{\prime} 43.8024^{\prime \prime} \mathrm{W}\right)$ had a prevalence $(69 \% ; 22$ out of 32) of infectious bovine keratoconjunctivitis (pink eye) upon arrival to the feedlot and were transported $313 \mathrm{~km} 10$ days prior to the beginning of the trail. Steers in this group were weaned, vaccinated against infectious bovine rhinotracheitis, parainfluenza-3 virus, bovine respiratory syncytial virus, bovine virus diarrhea Types I and II (Bovishield Gold 5, Zoetis, Kalamazoo, MI), Clostridium chauvoei, C. septicum, C. novyi, C. sordellii, C. perfringens types $\mathrm{C}$ and $\mathrm{D}$, and Haemophilus somnus (Ultrabac 7/Somubac, Zoetis, Kalamazoo, MI), and treated with an anthelmintic (Valbazen, Zoetis, Kalamazoo, MI) at time of weaning 72 days prior to beginning of the trial.

Seven days prior to initiation of the feeding experiment, all steers were treated with an anthelmintic (Dectomax, Zoetis, Kalamazoo, MI) and vaccinated against infectious bovine rhinotracheitis, parainfluenxe-3 virus, bovine respiratory syncytial virus, bovine virus diarrhea type I and II (Bovishield Gold One Shot, Zoetis, Zoetis, Kalamazoo, MI ), Clostridium chauvoei, C. septicum, C. novyi Type B, C. haeomolyticum, C. tetani, and C. perfringens types C and D (Covexin 8, Merck Animal Health, Madison, NJ).

Upon arrival to the feedlot, steers were placed into 1 of 10 partially covered pens. Steers were fed brome hay (88\% DM, 92\% OM, 63\% NDF, 40\% ADF, $8 \%$ CP) at 0700 
and 1600 daily leading up to initiation of the experiment. Immediately prior to the beginning of the experiment, steers were weighed across 2 consecutive days and beginning body weight was calculated as the average body weight on $d-1$ and 0 . Steers were stratified by body weight within source, and randomly assigned to 1 of 10 partially covered pens $(7.32 \mathrm{~m} \times 16.15 \mathrm{~m})$, with 8 steers per pen. Each pen was then fed a completely pelleted diet (Table 2.1), with monensin included at a rate of $39.6 \mathrm{mg} / \mathrm{kg}$ and either had cinnamaldehyde and capsicum essential oils added at $1 \%$ of the diet (DM basis; EO) or no additions of essential oils (CONTROL).

Steers were fed once daily at 0700 , for a total of 56 days. Daily feed offered to each pen was equally delivered across 2 semi-autonomous feed monitoring systems designed to measure individual animal intake and feeding behavior (GrowSafe System Ltd., Airdrie, Alberta, Canada). Animals were provided $26.04 \mathrm{~cm}$ of linear bunk space per animal. On the first day of the trial, steers were fed at $3 \%$ of body weight on a DM basis, based on the average body weight of each pen. Orts were collected daily and weighed for dry matter intake calculations. Subsequently, feed was then offered at amounts calculated to provide $110 \%$ of the previous $24 \mathrm{~h}$ as-fed intake.

\section{Chemical Analyses}

Feed samples were collected weekly and stored at $-4^{\circ} \mathrm{C}$ for chemical analyses. Ort samples were collected daily and stored at $-4^{\circ} \mathrm{C}$. Ort samples were then composited by week within pen.

Feed and ort samples were ground to pass through a 1-mm screen using a Wiley mill (No. 4, Thomas Scientific, Swedesboro, NJ) and analyzed for DM, OM, CP, NDF, 
$\mathrm{ADF}$, and ether extract. Dry matter content was measured by drying at $105^{\circ} \mathrm{C}$ for $16 \mathrm{~h}$, ash content was determined by incineration at $450^{\circ} \mathrm{C}$ for $16 \mathrm{~h}$, and organic matter content was calculated as the difference between 100 and the percent ash. Nitrogen was measured by combustion (method no. 990.03; AOAC, 2000) and CP was calculated as nitrogen $\times$ 6.25. Ether extract was measured gravimetrically after extraction with diethyl ether (method no. 920.39; AOAC, 2000; Goldfisch Fat Extractor, Labconco, Kansas City, MO). Neutral detergent fiber and ADF were determined non-sequentially using an ANKOM Fiber Analyzer (ANKOM Technology Corp., Fairport, NY). Sodium sulfite and $\alpha$-amylase were used in NDF analysis.

\section{Measurements and Calculations}

Feeding behavior was recorded across a 56-day feeding period using a semiautonomous feed intake monitoring system (GrowSafe Systems, Alberta, Canada). Each animal was equipped with an electronic identification tag (EID) that enabled measurements of start time, amount of time spent feeding, and intake of feed during each visit for each animal.

Feeding behavior was characterized using methods similar to those described by Tolkamp et al. (2000). Meal criteria were calculated before visits and were reported using data pooled across the entire feeding period. Intervals between visits were calculated for each steer from the end time of a visit and the start time of the next visit. Visit duration and mean intake per visit were determined from the average values per steer and calculated from total intake and total visit duration divided by the number of visits. One, two, and three Gaussians were fitted to the distribution of the log-transformed interval 
lengths between visits (Figure 3.1). Best fit was calculated using Akaike's information criterion, Bayesian information criterion, and corrected Akaike's information criterion (Figure 3.2). A model similar to Tolkamp et al. (2000) containing three Gaussians demonstrated the best fit: $\left.\mathrm{y}_{\log (\mathrm{t})}=\mathrm{p}^{*}\left(1 / \sigma_{1} \sqrt{2} \pi\right)\right)^{*} \exp \left(-\left(\log (\mathrm{t})-\mu_{1}\right)^{2} / 2 \sigma_{1}^{2}\right)+(1-\mathrm{p}-$ $\left.\left.\mathrm{q}) *\left(1 / \sigma_{2} \sqrt{ } 2 \pi\right)\right) * \exp \left(-\left(\log (\mathrm{t})-\mu_{2}\right)^{2} / 2 \sigma_{2}{ }^{2}\right)+\mathrm{q}^{*}\left(1 / \sigma_{3} \sqrt{2} \pi\right)\right)^{*} \exp \left(-\left(\log (\mathrm{t})-\mu_{3}\right)^{2} / 2 \sigma_{3}^{2}\right)$ With $\mathrm{y}_{\log (\mathrm{t})}=$ probability density at $\log (\mathrm{t}), \mathrm{p}=$ proportion of intervals belonging to the first distribution, $\sigma_{1}, \sigma_{2}$, and $\sigma_{3}=$ standard deviation of the first, second, and third distributions, $\operatorname{lot}(t)=$ natural logarithm of interval length (expressed in seconds), $\mu_{1}, \mu_{2}$, and $\mu_{3}=$ mean $\log$ (interval length) of the first, second, and third distributions, and $\mathrm{q}=$ proportion of intervals in the third population.

Mean interval lengths were back transformed and meal criteria were calculated as the interval length that contained at least $95 \%$ of intervals in the third Gaussian distribution (i.e., $95 \%$ confidence interval). After calculation of meal intervals, visits separated by intervals shorter than or equal to meal criteria were grouped into meals.

\section{Statistical Analysis}

One animal was removed from the experiment on day 6 due to an abscess on shoulder. The animal was replaced with an animal with the same prior stress and similar in weight.

The Finite mixed model of SAS (version 9.4, SAS INC., Cary, NC) was used to fit Gaussian distributions to the multimodal log transformations of feeding events, and to calculate intermeal intervals. Measures of feeding behavior were analyzed as repeated measures in a randomized complete block design using the Mixed procedures of SAS 
(version 9.4, SAS INC., Cary, NC). The model included the fixed effect of treatment, day, prior stress, and body weight block, and pen within each unique combination of prior stress and treatment were considered the random variable. Day was the repeated variable, steer within pen was the subject, and compound symmetry served as the covariate structure. Least square means were calculated using the LSMeans option and when the $F$-statistic was significant $(P \leq 0.05)$ means were separated using a student's ttest. Orthogonal polynomials were used to analyze linear and quadratic trends across days.

\section{RESULTS AND DISCUSSION}

The observations of intervisit intervals demonstrated a skewed distribution and asymmetrical variance (Tolkamp, 1998). Correspondingly, observations of intervisit intervals were pooled and log transformed to appropriately identify intermeal intervals. Meals for calves in this experiment were feeding events that began 28 minutes and 40 seconds after the end time of a previous visit. Tolkamp et al. (2000) reported an intermeal interval of 44.7 minutes. Tager and Krause (2011) observed feeding behavior with visually and defined intervals between meals as a period of eating activity at least 20 minutes after the end of a feeding event. Wangsness et al. (1976) also defined a meal interval as a period of eating activity 20 minutes after the end of a feeding event. The differences in meal intervals may be explained by the technique used to observe feeding events and to estimate meal criteria. Visual observations like those described in Tager and Krause (2011) are subjective compared to automated recordings of observations. Tager and Krause (2011) noted feeding activities every 5 minutes and assumed that each 
activity persisted for the entire 5-minute interval. However, automated observations, similar to GrowSafe systems, record measurements for each activity when an animal puts its head in the bunk and the EID is recorded. The technique used by Tolkamp et al. (2000) is similar to the technique used to estimate the meal criteria for the current study. Though, the differences in intervals between meals may be explained by the animals used, diets, feed monitoring systems used, and available bunk space.

Measures of DM, OM, CP, NDF, ADF, and ether extract are reported in Table 3.1. As expected, addition of EO to control had no impact on measures (mean \pm standard deviation) of DM (89.4 \pm 0.45$), \mathrm{OM}(90.5 \pm 0.53), \mathrm{CP}(12.7 \pm 0.58), \mathrm{NDF}(43.2 \pm 2.36)$ $\operatorname{ADF}(26.9 \pm 2.23)$ or ether extract $(3.5 \pm 0.37)$

Dry matter intake increased quadratically $(P<0.01$, Figure 3.4$)$ in increasing days on feed and was greatest on day 53. Additionally, steers exposed to moderate stress had greater $(P=0.02$; Table 3.2) DMI than steers exposed to small or large stress, and steers exposed to large stress tended $(P=0.07)$ to have greater DMI than steers exposed to small stress. Essential oil did not influence $(P=0.11)$ measures of DMI, though steers fed EO had numerically greater DMI than seers fed control. The lack of treatment effect on daily DMI conflicts with reported effects of DMI in Tager and Krause (2011), who observed overall DMI greater than those observed in the present study. Though, Tager and Krause (2011) fed EO to lactating dairy cows and the present study was conducted by feeding backgrounding steers. Rodriguez-Prado et al. (2012) reported an increase in DMI when heifers were supplemented with capsicum. Souza et al. (2019) reported that rosemary oil decreased DMI in heifers and Ornaghi et al. (2017) reported increases in DMI when bulls were supplemented with EO. This lack of treatment effects in the 
present study may conflict with the literature described due to differences in cattle production system and dose of EO used. The lack of effects of EO on DMI corresponds with the lack of effects reported by Geraci et al. (2012) and Carvalho et al. (2021).

Dry matter intake per meal was greatest on day 0 and subsequently decreased quadratically $(P<0.01$; Figure 3.5$)$. Also, stress tended $(P=0.08$; Table 3.2$)$ to affect DMI per meal. Steers exposed to moderate stress had greater DMI per meal $(P=0.03)$ than steers exposed to large stress, but DMI per meal for steers exposed to small stress was not different $(P \geq 0.24)$ than DMI per meal for steers exposed to moderate or large stress. Yet, EO did not impact DMI per meal $(P=0.82)$, nor was there a treatment by day interaction $(P=0.10)$.

Steers fed EO had a greater $(P \leq 0.03)$ feeding rate on days 11 and 44 (days on feed $\times$ diet, $P=0.02$; Figure 3.6) and tended $(P=0.09)$ to have a greater feeding rate on day 8 when compared to steers offered control. However, there were no differences ( $P \geq$ 0.14) observed between EO or control for any other day during the experiment. Feeding rate tended ( $P=0.06$, Figure 3.6) to increase linearly throughout the feeding experiment, but diet did not impact ( $P=0.98$, Table 3.2) feeding rate. Feeding rate for the present study was smaller than that reported by Tolkamp et al. (1998) and Tolkamp et al. (2000), who both reported feeding rates of $145.7 \mathrm{~g}$ per minute and $310.67 \mathrm{~g}$ per minute. These differences may be explained by diet type (concentrate vs. forage), animal type (lactating dairy cows vs. beef steers), and animal size.

Meal numbers increased quadratically $(P<0.01$; Figure 3.7$)$, and the greatest number of meals on day 4 . Stress tended $(P=0.09)$ to influence number of meals; steers 
exposed to large stress had a greater $(P=0.04)$ number of meals per day than steers exposed to small stress, but no differences $(P \geq 0.12)$ were observed for number of meals between steers exposed to moderate stress and steers exposed to small or large stress. The lack of effects of EO on number of meals is similar to the observations of Tager and Krause (2011) who also reported no effects of feeding EO on number of meals.

Meal duration was also influenced $(P<0.01$; Figure 3.8$)$ by days on feed, but meal duration increased quadratically $(P<0.01)$ to day 24 after initiation of the trial. Steers exposed to moderate stress had a greater $(P=0.02)$ meal duration than steers exposed to large stress and tended $(P=0.08)$ to have a greater meal duration than steers exposed to small stress, but no differences $(P=0.43)$ were observed between steers exposed to small or large stress. There was no effect $(P=0.28)$ of feeding EO or control on meal duration.

The meal duration in this study is smaller than meal duration in other studies. Tager and Krause (2011) reported an average meal duration of 33.9 minutes per meal when lactating dairy cows were fed a $42 \%$ forage and $58 \%$ concentrate total mixed ration (TMR) and supplemented with varying doses of cinnamaldehyde, eugenol, or capsicum oils, though in the study, differences across treatments were not significant. Tolkamp et al. (2000) reported an average meal duration of 36.9 minutes, which is approximately 8 minutes greater than the mean meal duration that was observed in the current study. These differences in mean meal duration may be explained through differences in diet type and animals used.

An interaction $(P<0.01$; Figure 3.9) between treatment and days on feed was observed for visit duration. Specifically, steers fed EO had a greater $(P<0.01)$ length of 
visits on days 10, 11, and 12 compared to steers offered control. However, steers fed control tended to have a greater $(P=0.06)$ visit duration on day 53 when compared with steers offered EO and no other differences $(P \geq 0.11)$ were observed between treatments at any other time point. Visit duration increased quadratically $(P<0.01)$ with visit duration greatest on day 10 . Visit duration conflicts with the data reported by Tolkamp et al. (2000), who reported an average visit duration of 25 minutes when lactating dairy cows were fed a TMR. These differences may be explained by diet type and animal type.

Similar to all other feeding behavior measures, an effect $(P<0.01$; Figure 3.10) of days on feed was observed for number of visits per meal. Specifically, number of visits per meal increased in a quadratic manner and were greatest on day 55 . Visits per meal tended ( $P=0.06$; Table 3.2) to differ among diet and stress. Steers fed EO and exposed to large stress had a greater $(P=0.04)$ number of visits per meal than steers offered control and exposed to the same stress. However, no differences $(P \geq 0.15)$ were observed between EO or control in steers exposed to small or moderate stress. Tolkamp et al. (2000) reported average visits per meal of 5.77, which is greater than the average number of visits per meal observed in the current study. This may be due to myriad differences.

\section{CONCLUSION}

Under the conditions of this experiment, the effect of EO on feeding behavior is modest. Effects of EO on feeding behavior may be due to type of EO used, dose of EO, and physiological status of the cattle used in the experiment. Efficacy of EO supplementation may depend on cattle physiological status, specific EO, and dose of EO. 
Figure 3.1. Frequency distribution of log normal interval length between visits to bunks.

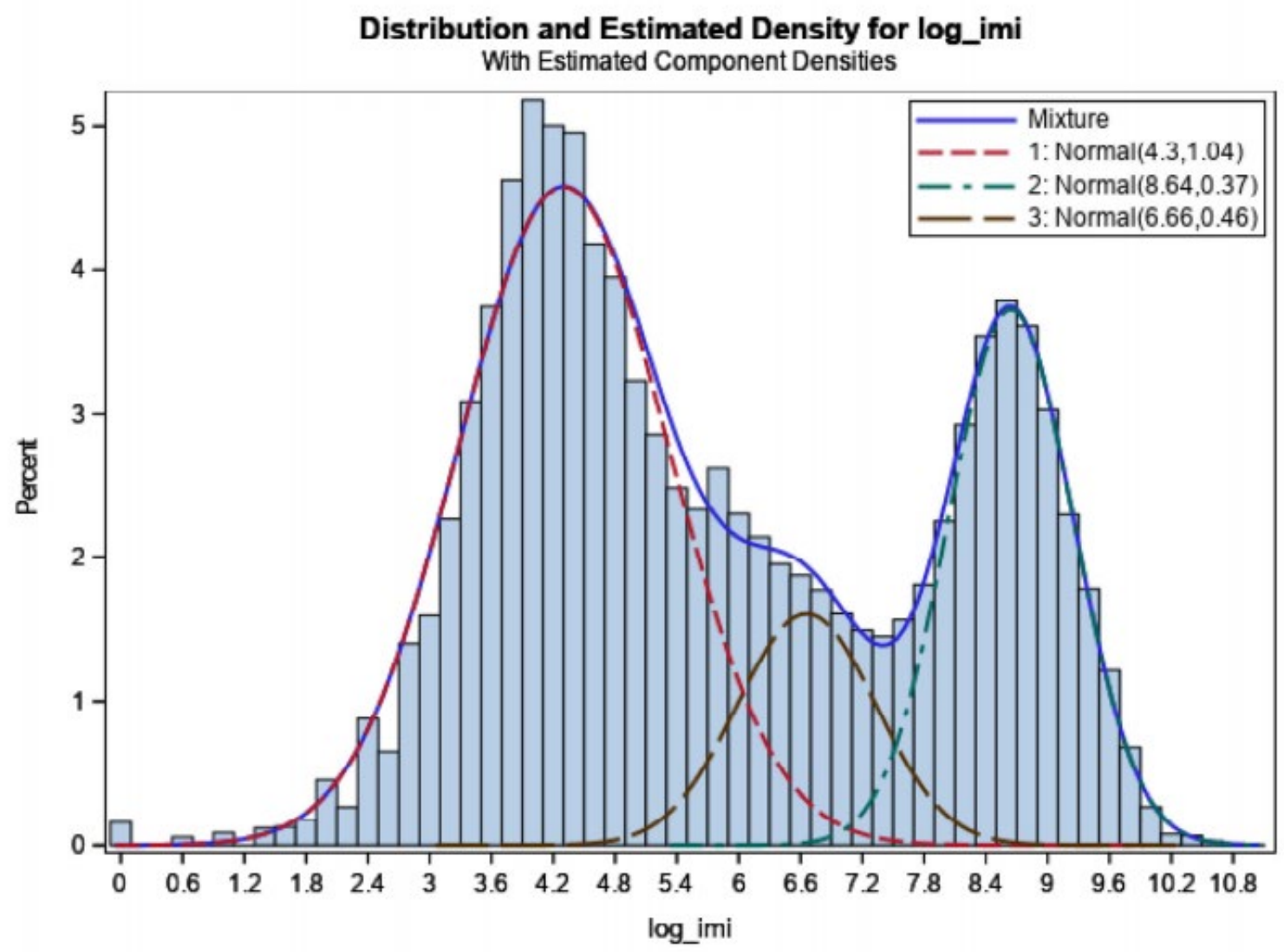


Figure 3.2 Best fit criteria progression.

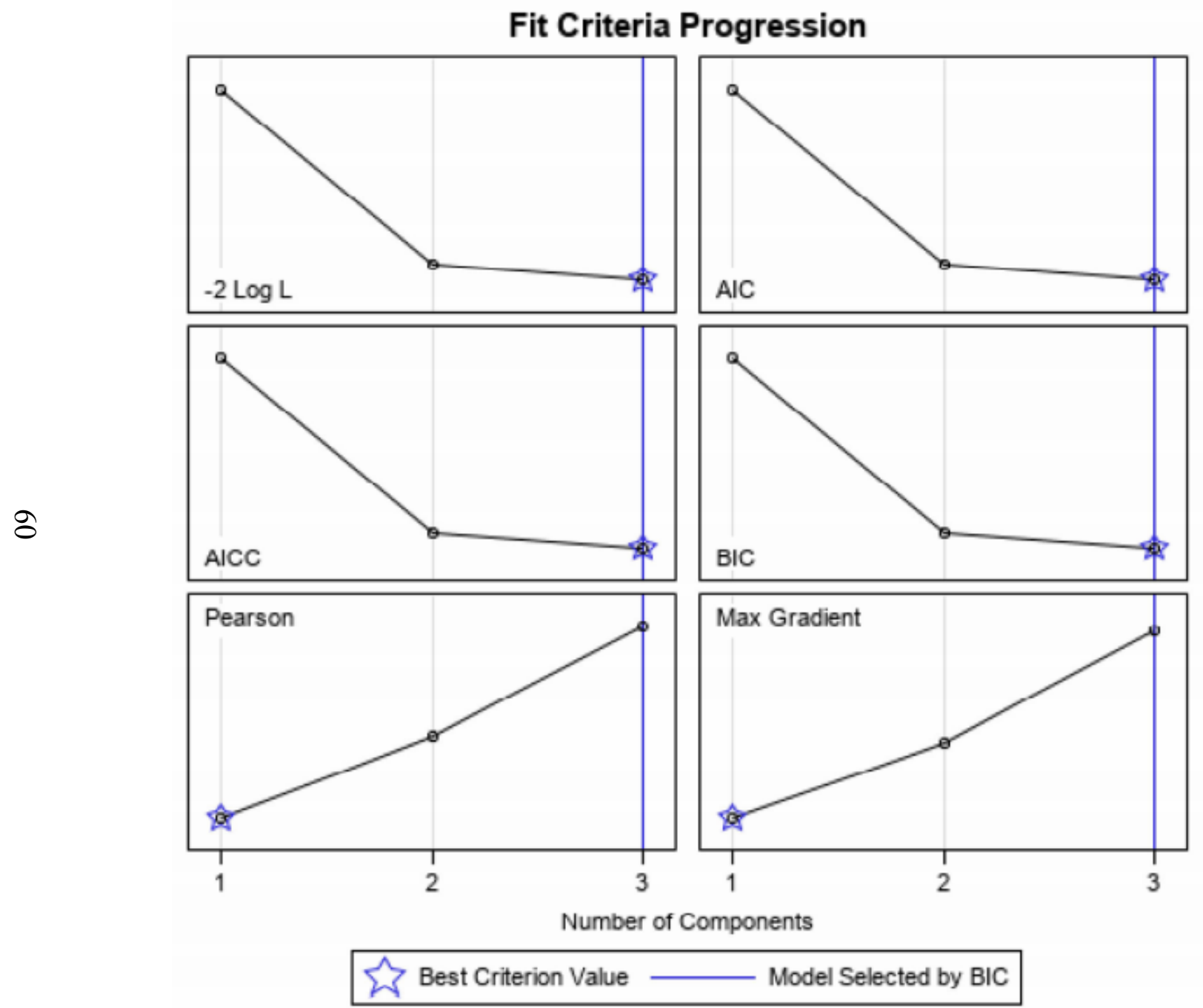


Figure 3.3. Density plot of intervisit intervals.

\section{Check Of IMI DATA}

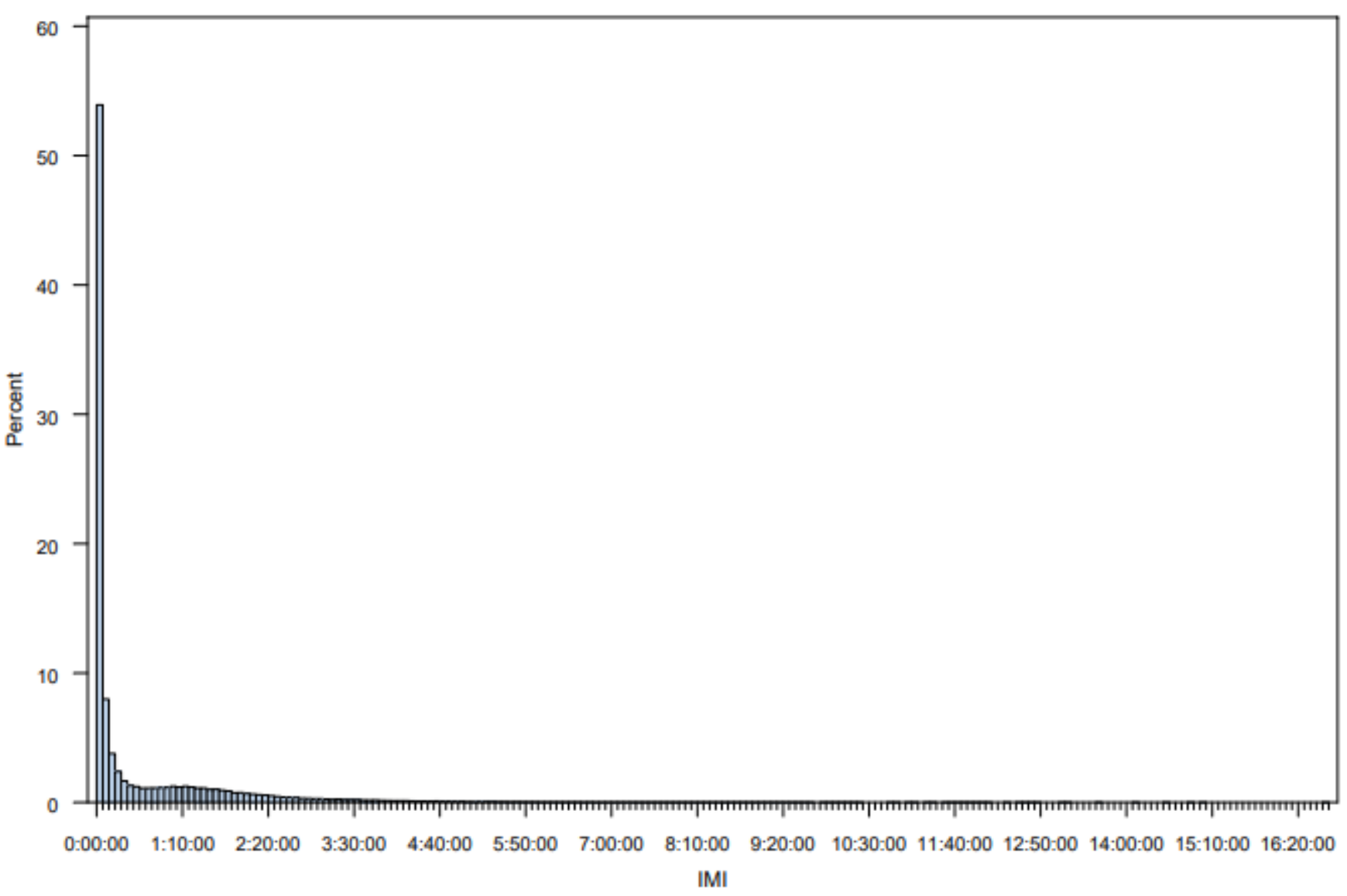


Table 3.1. Chemical composition of complete feed with essential oils (EO) or without essential oils (control).

\begin{tabular}{lcc}
\hline & \multicolumn{2}{c}{ Treatment } \\
\cline { 2 - 3 } Chemical composition, \% & Control & EO \\
\hline Dry matter & 89.67 & 89.22 \\
Organic matter & 90.36 & 90.57 \\
Crude protein & 12.32 & 13.01 \\
Neutral detergent fiber & 45.26 & 41.21 \\
Acid detergent fiber & 28.87 & 24.95 \\
Ether extract & 3.58 & 3.33 \\
\hline
\end{tabular}


Table 3.2. Effect of essential oils (EO) or control on feeding behavior characteristics in growing beef cattle fed a complete feed.

\begin{tabular}{|c|c|c|c|c|c|c|c|c|c|}
\hline & \multicolumn{2}{|c|}{ Small stress } & \multicolumn{2}{|c|}{ Moderate stress } & \multicolumn{2}{|c|}{ Large stress } & \multicolumn{3}{|c|}{$P$-values } \\
\hline & Control & $\mathrm{EO}$ & Control & $\mathrm{EO}$ & Control & $\mathrm{EO}$ & $\mathrm{D} \times \mathrm{PS}$ & Diet & Prior stress \\
\hline Total feed intake, $\mathrm{kg} / \mathrm{d}$ & 5.71 & 6.30 & 7.07 & 7.39 & 6.53 & 6.66 & 0.63 & 0.11 & 0.02 \\
\hline $\begin{array}{l}\text { Feed intake per meal, } \\
\mathrm{kg}\end{array}$ & 0.86 & 0.83 & 0.87 & 0.94 & 0.78 & 0.77 & 0.61 & 0.82 & 0.08 \\
\hline No. of meals per day & 7.76 & 8.51 & 8.88 & 8.68 & 9.39 & 9.48 & 0.55 & 0.54 & 0.09 \\
\hline Meal duration, min & 30.06 & 24.23 & 34.23 & 35.10 & 26.15 & 26.15 & 0.53 & 0.28 & 0.39 \\
\hline Visit duration, min & 5.08 & 4.59 & 4.96 & 4.93 & 3.59 & 4.04 & 0.65 & 0.95 & 0.10 \\
\hline No. of visits per meal & 2.98 & 2.97 & 3.25 & 3.60 & 3.65 & 3.04 & 0.06 & 0.54 & 0.15 \\
\hline Feeding rate, $\mathrm{g} / \mathrm{min}$ & 81.64 & 56.52 & 72.11 & 67.03 & 68.00 & 99.03 & 0.26 & 0.98 & 0.54 \\
\hline
\end{tabular}

$\mathrm{SEM}=$ Standard error of the mean 
Figure 3.4. Effect of essential oils (EO) or control (CON) on daily dry matter intake of growing beef cattle fed a complete feed. Treatment, $\mathrm{P}=0.11$; Day, $\mathrm{P}<0.01$; Treatment $\times$ day interaction, $\mathrm{P}=0.40 ; \mathrm{SEM}=0.30$

Dry Matter Intake

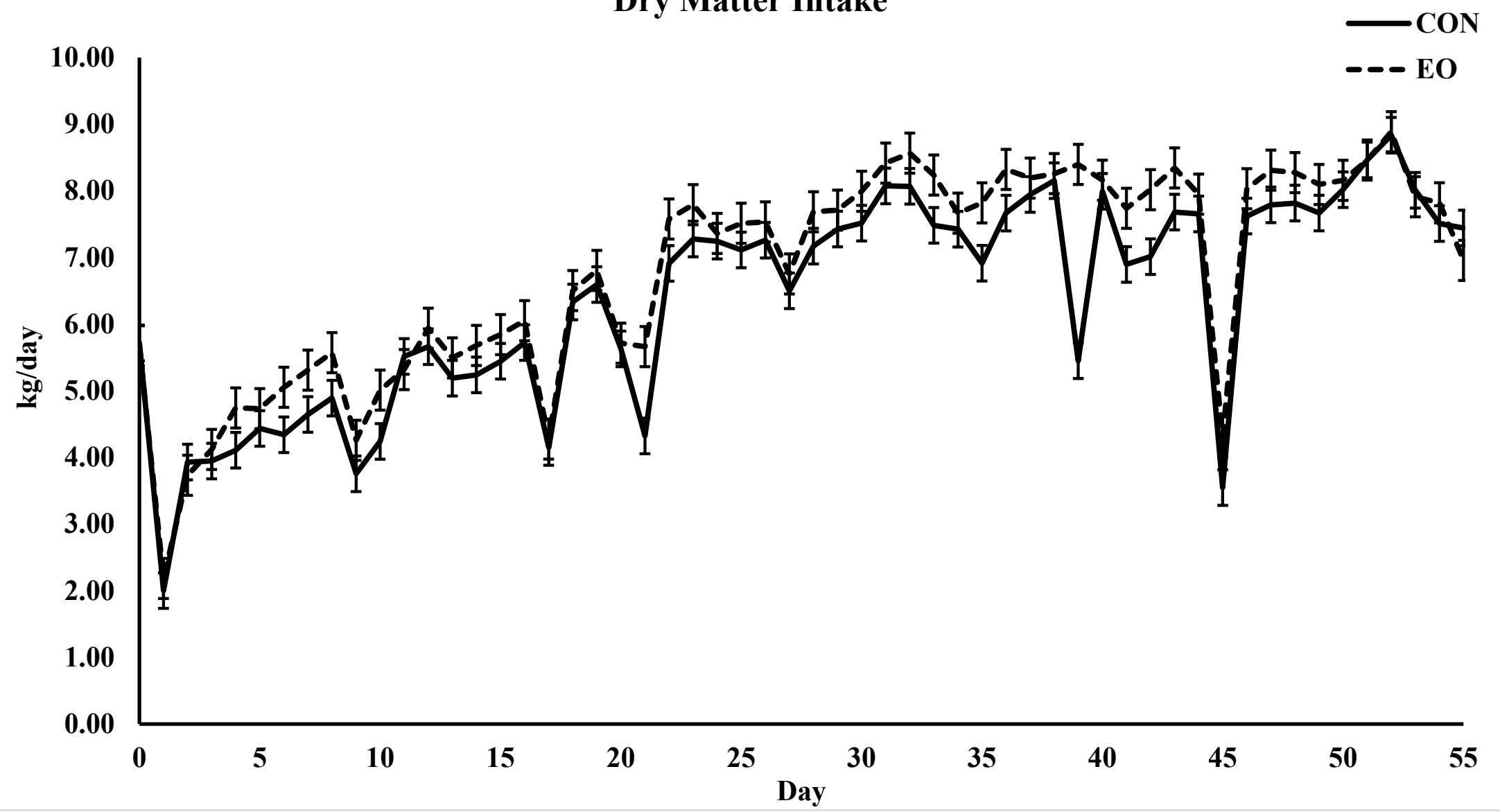


Figure 3.5. Effect of essential oils(EO) or control $(\mathrm{CON})$ on dry matter intake per meal in growing beef cattle fed a complete feed. Treatment, $\mathrm{P}=0.82$; Day, $\mathrm{P}<0.01$; Treatment $\times$ day interaction, $\mathrm{P}=0.10 ; \mathrm{SEM}=61.84$

Dry Matter Intake

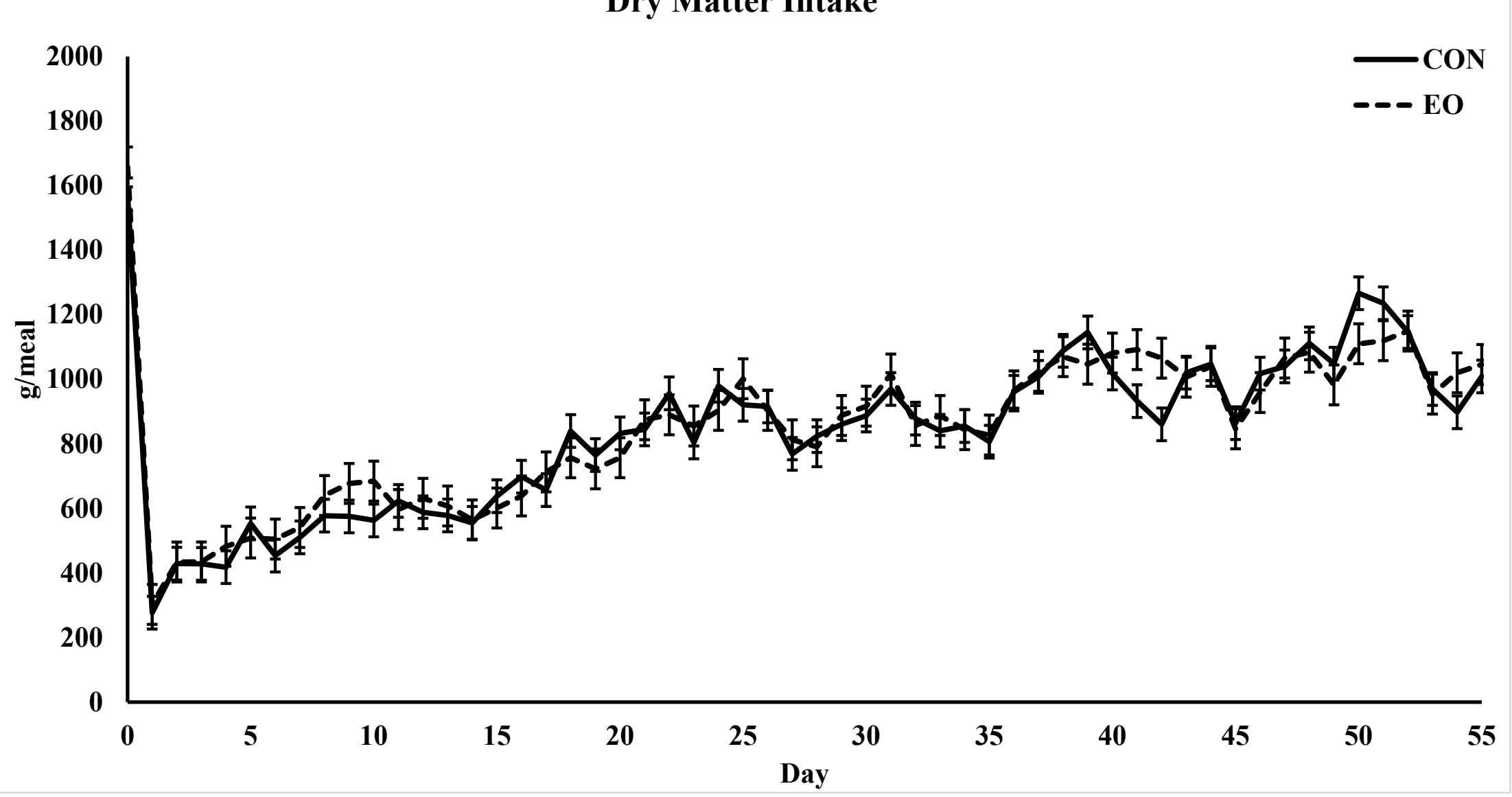


Figure 3.6. Effect of essential oils (EO) or control (EO) on feeding rate of growing beef cattle fed a complete feed. Treatment $\times$ day interaction, $\mathrm{P}=0.02 ; \mathrm{SEM}=35.80$

\section{Feeding rate}

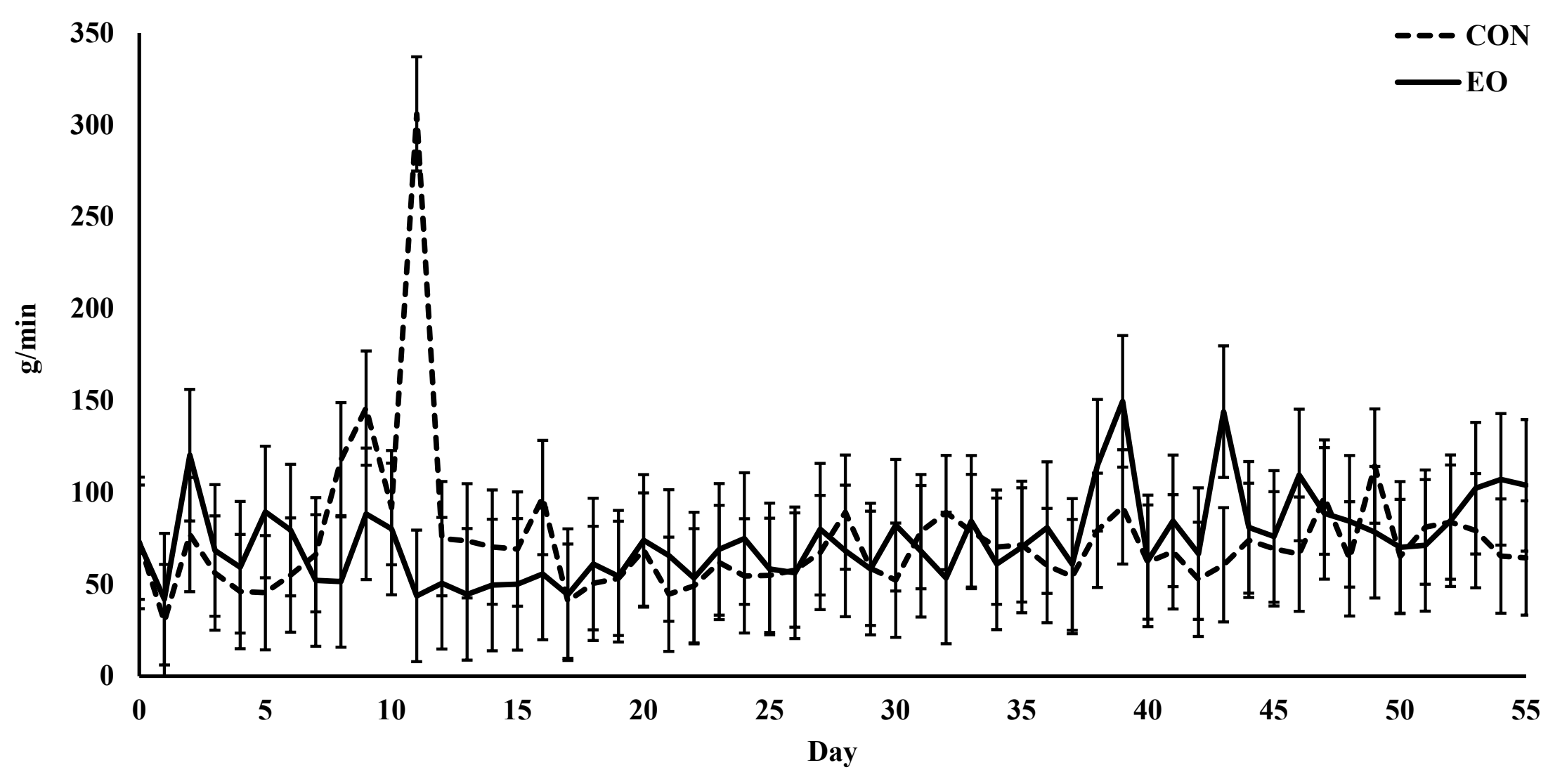


Figure 3.7. Effect of essential oils (EO) or control (CON) on number of meals per day in growing beef cattle fed a complete feed. Treatment, $\mathrm{P}=0.54$; Day, $\mathrm{P}<0.01$; Treatment $\times$ day interaction, $\mathrm{P}=0.89 ; \mathrm{SEM}=0.45$

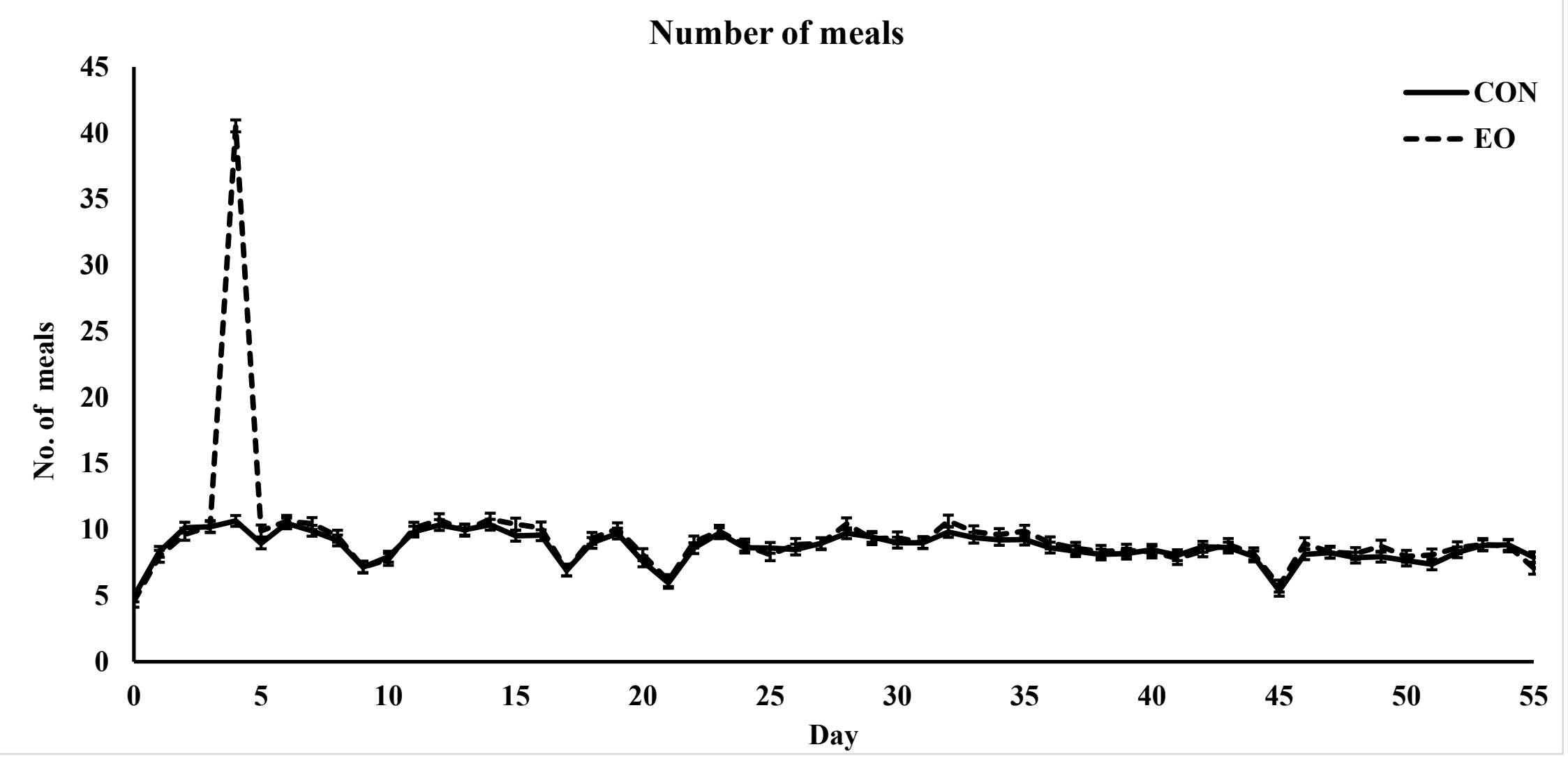


Figure 3.8. Effect of essential oils (EO) or control (CON) on meal duration in growing beef cattle fed a complete feed. Treatment, $\mathrm{P}=0.28$; Day, $\mathrm{P}<0.01$; Treatment $\times$ day interaction, $\mathrm{P}=0.39 ; \mathrm{SEM}=5.33$

\section{Meal duration}

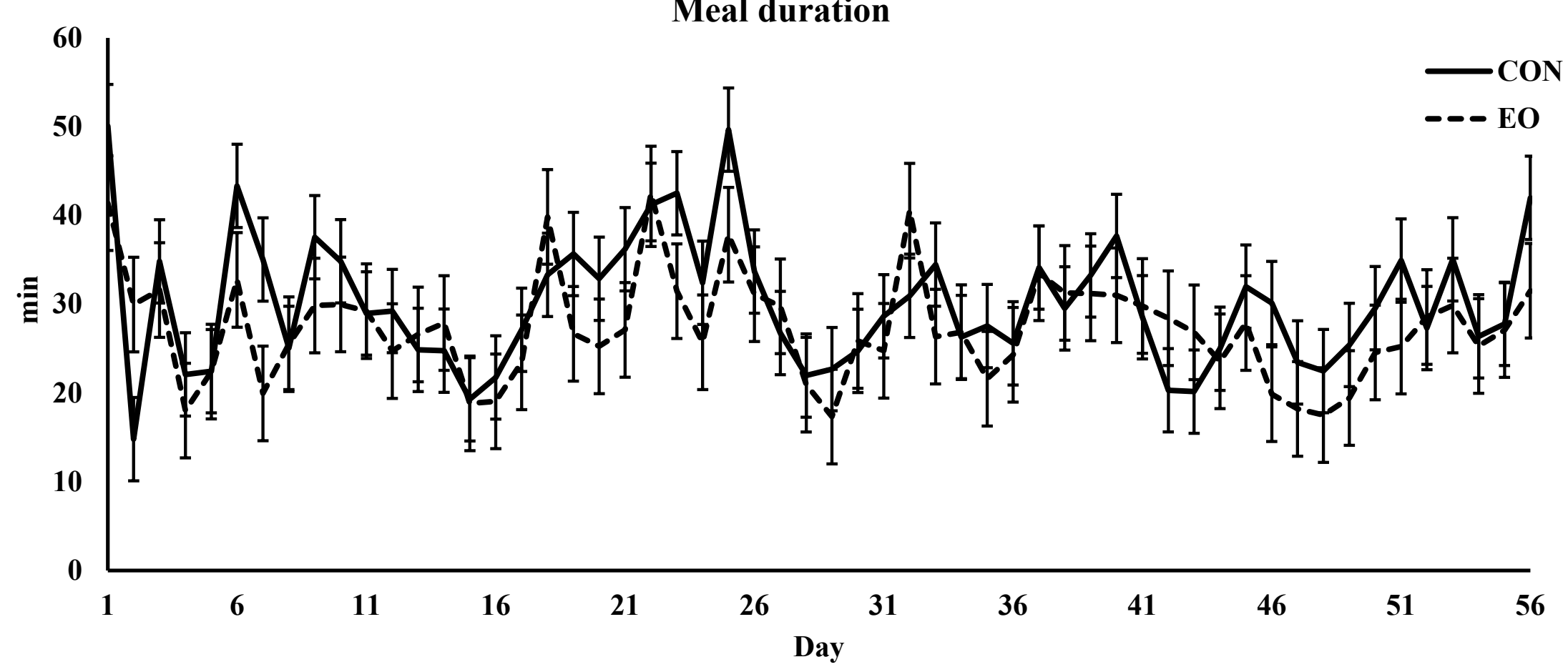


Figure 3.9. Effect of essential oils (EO) or control $(\mathrm{CON})$ on visit duration in growing beef cattle fed a complete feed. Treatment $\times$ day interaction, $\mathrm{P}<0.01 ; \mathrm{SEM}=0.51$

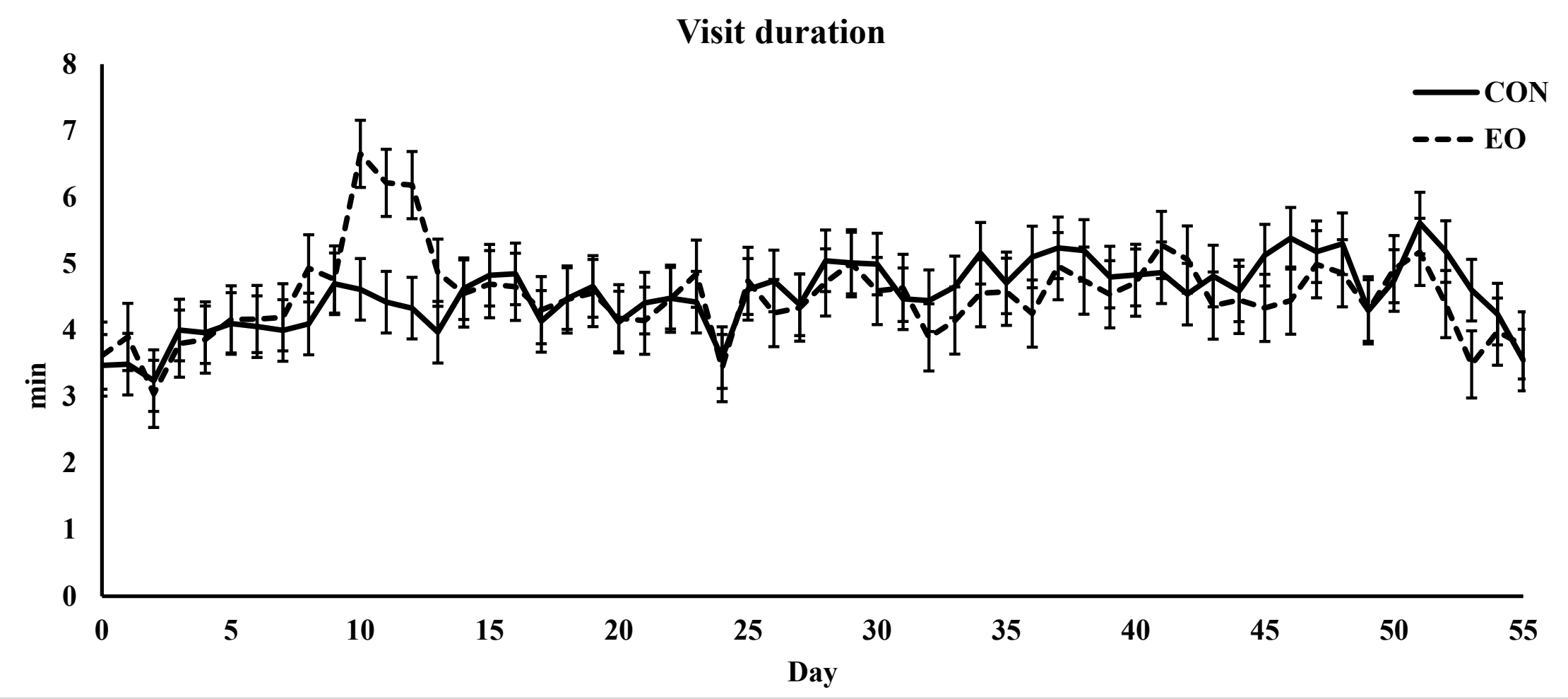


Figure 3.10. Effect of essential oils (EO) or control $(\mathrm{CON})$ on number of visits per meal in growing beef cattle fed a complete feed. Treatment, $\mathrm{P}=0.54$; Day, $\mathrm{P}<0.01$; Treatment $\times$ day interaction, $\mathrm{P}=0.48 ; \mathrm{SEM}=0.28$

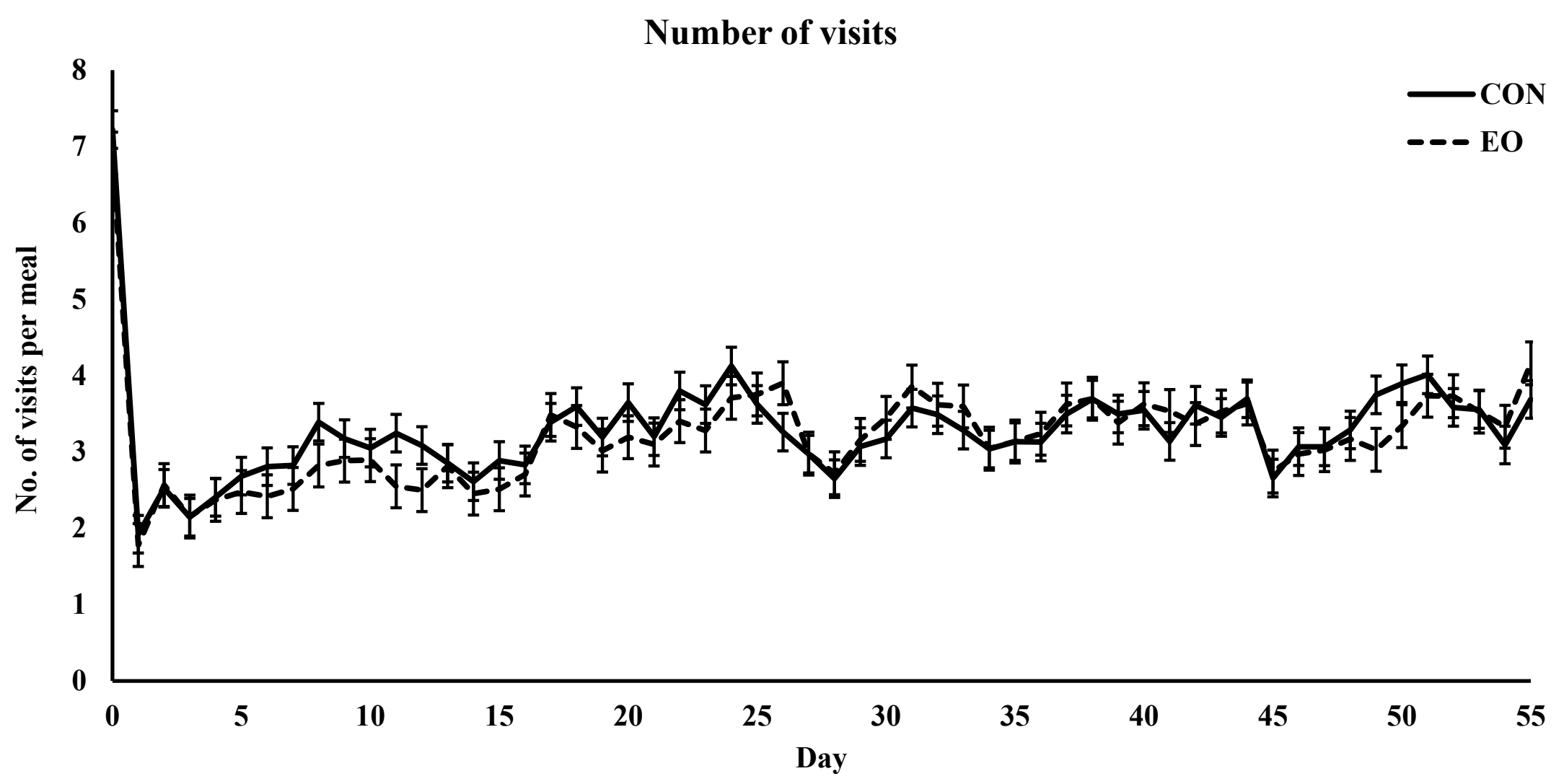




\section{LITERATURE CITED}

Abbas, A. K., A. H. Lichtman, and S. Pillai. 2018. Cellular and Molecular Immunology. Ninth edition. Elsevier. Philadelphia, PA. Accessed May 28, 2021. https://www.clinicalkey.com/\#!/browse/book/3-s2.0-C20150023565.

Acamovic, T. and J. D. Brooker. 2005. Biochemistry of plant secondary metabolites and their effects in animals. In Symposium on "Plants as animal foods: a case of catch 22” Proc. Nutr. Soc. 64:403-412. doi:10.1079/PNS2005449.

Anassori, E., B. Dalir-Nahhadeh, R. Pirmohammadi, A. Taghizadeh, S. Asri-Rezaei, M. Maham, S. Farahmand-Azar, P. Farhoomand. 2011. Garlic: A potential alternative for monensin as a rumen modifier. Livest. Sci. 142:276-287. doi:10.1016/j.livsci.2011.08.003.

Baptiste, K. E. and N. C. Kyvsgaard. 2017. Do antimicrobial mass medications work? A systematic review and meta-analysis of randomized clinical trials investigating antimicrobial prophylaxis or metaphylaxis against naturally occurring bovine respiratory disease. Pathog. Dis. 75:7. doi:10.1093/femspd/ftx083.

Benchaar, C., J. L. Duynisveld, and E. Charmley. 2006. Effect of monensin and increasing dose levels of a mixture of essential oil compounds on intake, digestion and growth performance of beef cattle. Can. J. Anim. Sci. 87:413-419.

Benchaar, C., H. V. Petit, R. Berthiaume, D. R. Ouellet, J. Chiquette, and P. Y. Chouinard. 2007. Effects of essential oils on digestion, rumen fermentation, rumen microbial populations, milk production, and milk composition in dairy 
cows fed alfalfa silage or corn silage. J. Dairy Sci. 90:886-897.

doi:10.3168/jds.S0022-0302(07)71572-2.

Benchaar, C., S. Calsamiglia, A. V. Chaves, G. R. Fraser, D. Colombatto, T. A. McAllister, K. A. Beauchemin. 2008. A review of plant-derived essential oils in ruminant nutrition and production. Anim. Feed. Sci. Technol. 145:209-228. doi:10.1016/j.anifeedsci.2007.04.014.

Bittner, C., 2012. Evaluation of soybean hulls and feed additives in finishing beef diets. M.S. Thesis. University of Nebraska, Lincoln. Accessed March 23, 2021. https://digitalcommons.unl.edu/cgi/viewcontent.cgi?article=1063\& context=anima 1scidiss

Bittner, C., 2016. Effects of feed additives and body weight on growth performance and carcass characteristics of beef finishing cattle. Ph.D. Dissertation. University of Nebraska, Lincoln. Accessed March 8, 2021. https://digitalcommons.unl.edu/cgi/viewcontent.cgi?article=1140\&context=anima 1scidiss

Burt, S., 2004. Essential oils: Their antibacterial properties and potential applications in foods-a review. Int. J. Food Microb. 94: 223-253. doi:10.1016/j.ijfoodmicro.2004.03.022.

Calsamiglia, S., M. Busquet, P. W. Cardozo, L. Castillejos, and A. Ferret. 2007. Invited Review: Essential oils as modifiers of rumen microbial fermentation. J. Dairy. Sci. 90:2580-2595. doi:10.3168/jds.2006-644. 
Cardozo, P. W., S. Calsamiglia, A. Ferret, and C. Kamel. 2006. Effects of alfalfa extract, anise, capsicum, and a mixture of cinnamaldehyde and eugenol on ruminal fermentation and protein degradation in beef heifers fed a high-concentrate diet. J. Anim. Sci. 84:2801-2808. doi:10.2527/jas.220-593.

Caroprese, M., A. Marzano, G. Entrican, S. Wattegedera, M. Albenzio, and A. Sevi. 2009. Immune response of cows fed polyunsaturated fatty acids under high ambient temperatures. J. Dairy. Sci. 92:2796-2803. doi:10.3168/jds.2008-1809.

Carvalho, V. M., V. A. D. Avila, E. Bonin, A. M. Matos, R. M. d. Prado, R. A. Castilho, R. R. Silva, B. A. d. A. Filho, I. N. d. Prado. 2021. Effect of extracts from baccharis, tamarind, cashew nut shell liquid and clove on animal performance, feed efficiency, digestibility, rumen fermentation and feeding behavior of bulls finished in feedlot. Livest. Sci. 244:104361. doi:10.1016/j.livsci.2020.104361.

Castillejos, L., S. Calsamiglia, A. Ferret, and R. Losa. 2007. Effects of dose and adaptation time of a specific blend of essential oil compounds on rumen fermentation. Anim. Feed Sci. Technol. 132:186-201. doi:10.1016/j.anifeedsci.2006.03.023.

Duff, G. C., and M. L. Galyean. 2007. Board-Invited Review: Recent advances in management of highly stressed, newly received feedlot cattle. J. Anim. Sci. 85:823-840. doi:10.2527/jas.2006-501. 
Edwards, R. and J. A. Gatehouse. 1999. Secondary metabolism. In plant biochemistry and molecular biology, pp. 193-218 [PJ Lea and RC Leegood, editors]. Chichester, West Sussex: John Wiley \& Sons Ltd.

El-Essawy, A. M., U. Y. Anele, A. M. Abdel-Wahed, A. R. Abdou, and I. M. Khattab. 2021. Effects of anise, clove and thyme essential oils supplementation on rumen fermentation, blood metabolites, milk yield and milk composition in lactating goats. Anim. Feed Sci. Technol. 271:114760.

doi:10.1016/j.anifeedsci.2020.114760.

European Medicines Agency (EMA). 2016. Revised guideline for the demonstration of efficacy for veterinary medicinal products containing antimicrobial substances. (EMA/CVMP/627/2001- Rev.1). Accessed May 13, 2021. https://www.ema.europa.eu/en/documents/scientific-guideline/final-guidelinedemonstration-efficacy-veterinary-medicinal-products-containingantimicrobial_en.pdf.

FDA. 2020. FACT SHEET: Veterinary Feed Directive Final Rule and Next Steps. Accessed May 13, 2021. https://www.fda.gov/animal-veterinary/developmentapproval-process/fact-sheet-veterinary-feed-directive-final-rule-and-next-steps.

Felix, T. L. 2017. Ionophores a technology to improve cattle production efficiency. Penn State Extension. Accessed January 19, 2021. https://extension.psu.edu/ionophores-a-technology-to-improve-cattle-efficiency. 
Galyean, M. L., G. C. Duff, and K. J. Malcolm-Callis. 1995. Management factors to decrease health problems in weaned calves. The Range Beef Cow Symposium XIV. Accessed January 15, 2021. https://digitalcommons.unl.edu/rangebeefcowsymp/180/?utm_source=digitalcommons.unl.edu \%2Frangebeefcowsymp $\% 2 F 180 \& u t m \_$medium $=$PDF\&utm_campaign=PDFCove rPages.

Galyean, M. L., L. J. Perino, and G. C. Duff. 1999. Interaction of cattle health/immunity and nutrition. J. Anim. Sci. 77:1120-1134. doi.org/10.2527/1999.7751120x.

Geraci, J. I., A. D. Garciarena, G. A. Gagliostro, K. A. Beauchemin, D. Colombatto. 2012. Plant extracts containing cinnamaldehyde, eugenol and capsicum oleoresin added to feedlot cattle diets: Ruminal environment, short term intake pattern and animal performance. Anim. Feed Sci. Technol. 176:123-130. doi:10.1016/j.anifeedsci.2012.07.015.

Greathead, H. 2003. Plants and plant extracts for improving animal productivity. Proc. Nutr. Soc. 62:279-290. doi:10.1079/PNS2002197.

Griffin S. G., S. G. Wyllie, J. L. Markham, and D. N. Leach. 1999. The role of structure and molecular properties in terpenoids in determining their antimicrobial activity. Flavour Fragr. J. 14:322-332. doi:10.1002/(SICI)10991026(199909/10)14:5\%3C322::AID-FFJ837\%3E3.0.CO;2-4. 
Hart, K. J., D. R. Yáñex-Ruiz, S. M. Duval, N. R. McEwan, C. J. Newbold. 2008. Plant extracts to manipulate rumen fermentation. Anim. Feed Sci. Technol. 147:8-35. doi:10.1016/j.anifeedsci.2007.09.007.

Helander, I. M., H. Alakomi, K. Latva-Kala, T. Mattila-Sandholm, I. Pol, E. J. Smid, L. G. M. Gorris, and A. Wright. 1998. Characterization of the action of selected essential oil components on gram-negative bacteria. J. Agric. Food Chem. $46: 3590-3595$

Hersom, M. and T. Thrift. 2012. Application of Ionophores in Cattle Diets. Institute of Food and Agricultural Sciences. Extension. University of Florida. Gainesville, Florida. Accessed January 19, 2021. https://edis.ifas.ufl.edu/an285.

Hoffman, C., and C. A. Evans. 1911. The use of spices as preservatives. J. Ind. Eng. Chem. 3:835-838. Accessed May 13, 2021. https://pubs.acs.org/doi/pdf/10.1021/ie50035a016.

Hosoda, K., K. Kuramoto, B. Eruden, T. Nishida, and S. Shioya. 2006. The effects of three herbs as feed supplements on blood metabolites, hormones, antioxidant activity, igg concentration, and ruminal fermentation in holstein steers. AsianAust. J. Anim. Sci. 1:35-41. doi:10.5713/ajas.2006.35.

Ives, S. E., and J. T. Richeson. 2015. Use of antimicrobial metaphylaxis for the control of bovine respiratory disease in high-risk cattle. Vet. Clin. Food Anim. 31:341-350. doi:10.1016/j.cvf.2015.05.008. 
Landers, T. F., B. Cohen, T. E. Wittum, and E. L. Larson. 2012. A review of antibiotic use in food animals: perspective, policy, and potential. Public Health Rep. 127:422. doi:10.1177/003335491212700103.

Lofgreen, G. P. 1983. Nutrition and management of stressed beef calves. In: Veterinary Clinics of North America: Large Animal Practice. pp 87-101. Vol. 5, No. 1, March 1983. 10.1016/s0196-9846(17)30094-0. Accessed June 21, 2021.

Meyer, N. F., G. E. Erickson, T. J. Kloptenstein, M. A. Greenquist, M. K. Luebbe, P. Williams, and M. A. Engstrom. 2009. Effect of essential oils, tylosin, and monensin on finishing steer performance, carcass characteristics, liver abscesses, ruminal fermentation, and digestibility. J. Anim. Sci. 87:2346-2354. doi:10.2527/jas.2008-1493.

Newbold, C. J., F. M. McIntosh, P. Williams, R. Losa, and R. J. Wallace. 2004. Effects of a specific blend of essential oil compounds on rumen fermentation. Anim. Feed Sci. Technol. 114:105-112. doi:10.1016/j.anifeedsci.2003.12.006.

Newman, D. J., G. M. Cragg, and K. M. Snader. 2000. The influence of natural products upon drug discovery. Nat. Prod. Rep. 17:215-234. doi:10.1039/a902202c.

Ornaghi, M. G., R. A. C. Passetti, J. A. Torrecilhas, C. Mottin, A. C. P. Vital, A. Guerrero, C. Sanudo, M. d. M. Campo, I. N. Prado. 2017. Essential oils in the diet of young bulls: Effect on animal performance, digestibility, temperament, feeding behaviour and carcass characteristics. Anim. Feed Sci. Technol. 234:274-283. doi:10.1016/j.anifeedsci.2017.10.008. 
Parish, J. 2010. Compensatory gain in cattle. In: Cattle Business in Mississippi: "Beef Production Strategies". https://extension.msstate.edu/sites/default/files/topicfiles/cattle-business-mississippi-articles/cattle-business-mississippi-articleslanding-page/mca_junjul2010.pdf. Accessed June 21, 2021.

Patra, A. K. 2012. An overview of antimicrobial properties of different classes of phytochemicals. Diet Phytochemicals and Microbes: Dordrecht, Springer Netherlands, pg. 1-32. doi:10.1007/978-94-007-3926-0_1.

Potter, E. L., M. I. Wray, R. D. Muller, H. P. Grueter, J. McAskill, and D. C. Young. 1985. Effect of monensin and tylosin on average daily gain, feed efficiency and liver abscess incidence in feedlot cattle. J. Anim. Sci. 61:1058-1065. doi:10.2527/jas1985.6151058x.

Reddy, P. R. K., M. M. M. Y. Elghandour, A. Z. M. Salem, D. Yasaswini, P. P. R. Reddy, A. N. Reddy, I. Hyder. 2020. Plant secondary metabolites as feed additives in calves for antimicrobial stewardship. Anim. Feed Sci. Technol. 264:114469. doi:10.1016/j.anifeedsci.2020.114469.

Rodriguez-Prado, M., A. Ferret, J. Zweiten, L. Gonzalez, D. Bravo, and S. Calsamiglia. 2008. Effects of dietary addition of capsicum extract on intake, water consumption, and rumen fermentation of fattening heifers fed a high-concentrate diet. J. Anim. Sci. 2012.90:1-6. doi:10.2527/jas2010-3191. 
Sewell, H. B. 1993. Feed additives for beef cattle. Department of Animal Sciences. University of Missouri-Columbia, Agricultural publication GO2075. Accessed January 25, 2021. https://mospace.umsystem.edu/xmlui/handle/10355/72635.

Sharifi-Rad, J., A. Sureda, G. C. Tenore, M. Daglia, M. Sharifi-Rad, M. Valussi, R. Tundis, M. Sharifi-Rad, M. R. Loizzo, A. O. Ademiluyi, R. Sharifi-Rad, S. A. Ayatollahi, and M. Iriti. 2017. Biological activites of essential oils: From plant chemoecology to traditional healing systems. Molecules 22:77. doi:10.3390/molecules22010070.

Sikkema, J., J. A. M. Bont, and B. Poolman. 1994. Interactions of cyclic hydrocarbons with biological membranes. J. Biol. Chem. 269:8022-8028. doi:10.1016/S00219258(17)37154-5.

Sneeringer, S., J. MacDonald, N. Key, W. McBride, and K. Mathews. 2015. Economics of antibiotic use in U.S. livestock production. USDA. Economic Research Report 200. Accessed April 14, 2021. https://papers.ssrn.com/sol3/papers.cfm?abstract_id=2981692.

Sompayrac L. 2019. How the Immune System Works. Sixth edition. Wiley Blackwell. Hoboken, NJ. Accessed May 28, 2021. https://search.ebscohost.com/login.aspx?direct=true $\& d b=$ cat04885a $\& A N=$ merlin. b13011676\&site=eds-live \&scope=site.

Souza, K. A. d., J. d. O. Monteschio, C. Mottin, T. R. Ramos, L. A. d. M. Pinto, C. E. Eiras, A. Guerrero, I. N. d. Prado. 2019. Effects of diet supplementation with 
clove and rosemary essential oils and protected oils (eugenol, thymol, vanillin) on animal performance, carcass characteristics, digestibility, and ingestive behavior activities for Nellore heifers finished in feedlot. Livest. Sci. 220:190-195. doi:10.1016/j.livsci.2018.12.026.

Tager, L. R. and K. M. Krause. 2011. Effects of essential oils on rumen fermentation, milk production, and feeding behavior in lactating dairy cows. J. Dairy. Sci. 94:2455-2464. doi:10.3168/jds.2010-3505.

Tolkamp, B. J., D. J. Allcroft, E. J. Austin, B. L. Nielsen, and I. Kyriazakis. 1998. Satiety splits feeding behaviour into bouts. J. Theor. Biol. 194:235250. doi:10.1006/htbi.1998-0759.

Tolkamp, B. J., D. P. N. Schweitzer, and I. Kyriazakis. 2000. The biologically relevant unit for the analysis of short-term feeding behavior of dairy cows. J. Dairy. Sci. 83:2057-2068. doi:10.3168/jds.S0022-0302(00)75087-9.

Ultee A., E. P. W. Kets, and E. J. Smid. 1999. Mechanisms of action of carvacrol on the food-borne pathogen Bacillus cereus. Appl. Environ. Microbiol. 65:4606-4610. doi: 10.1128/AEM.65.10.4606-4610.1999.

Vogel, G. J., and S. B. Laudert. 1994. The influence of tylan on liver abscess control and animal performance - A 40 trial summary. J. Anim. Sci. 72(Suppl. 1):293. Abstr.).

Wallace, R. J. 2004. Antimicrobial properties of plant secondary metabolites. In Symposium on "Plants as animal foods: a case of catch 22". Proc. Nutr. Soc. 63:621-629. doi:10.1079/PNS2004393. 
Wangsness, P. J., L. E. Chase, A. D. Peterson, T. G. Hartsock, D. J. Kellmel, and B. R. Baumgardt. 1976. System for monitoring feeding behavior of sheep. J. Anim. Sci. 42:1544-1549. doi:10.2527/jas1976.4261544x.

Westerhold, M. C., 2013. Essential oil effects on rumen fermentation, animal performance, and meat quality of beef steers. M.S. Thesis. University of Missouri, Columbia. Accessed December 22, 2020. https://mospace.umsystem.edu/xmlui/bitstream/handle/10355/43035/research.pdf ?sequence $=1 \&$ isAllowed $=\mathrm{y}$.

Wilson, B. K. 2014. Ancillery therapy use and trace mineral supplementation in beef cattle: impacts on clinical health, immune response variables, animal performance, and carcass traits. Ph.D. Dissertation. Oklahoma State University, Stillwater. Accessed February 25, 2021. https://core.ac.uk/download/pdf/215291593.pdf.

Wilson, B. K., C. J. Richards, D. L. Step, and C. R. Krehbiel. 2017. Best management practices for newly weaned calves for improved health and well-being. J. Anim. Sci. 2017.95:2170-2182. doi:10.2527/jas2016.1006. https://academic.oup.com/jas/article/95/5/2170/4703679?searchresult=1.

Wolfger, B., K. S. Schwartzkopf-Genswein, H. W. Barkema, E. A. Pajor, M. Levy, and K. Orsel. 2015. Feeding behavior as an early predictor of bovine respiratory disease in North American feedlot systems. J. Anim. Sci 2015.93:377-385. doi:10.2527/jas2013-8030. 
Woolums, A. R., G. H. Loneragan, L. L. Hawkins, and S. M. Williams. 2005. Baseline management practices and animal health data reported by US feedlots responding to a survey regarding acute interstitial pneumonia. Bov. Pract. 39:116-124. doi:10.21423/bovine-vol39no2p116-124.

Yang, W. Z., C. Benchaar, B. N. Ametaj, A. V. Chaves, M. L. He, and T. A. McAllister. 2007. Effects of garlic and juniper berry essential oils on ruminal fermentation and on the site and extent of digestion in lactating cows. J. Dairy Sci. 90:56715681. doi:10.3168/jds.2007-0369.

Yang, W. Z., B. N. Ametaj, C. Benchaar, and K. A. Beauchemin. 2010a. Dose response to cinnamaldehyde supplementation in growing beef heifers: Ruminal and intestinal digestion. J. Anim. Sci. 88:680-688. doi:10.2527/jas.2008-1652.

Yang, W. Z., B. N. Ametaj, C. Benchaar, M. L. He, and K. A. Beauchemin. 2010 b. Cinnamaldehyde in feedlot cattle diets: Intake, growth performance, carcass characteristics, and blood metabolites. J. Anim. Sci. 88:1082-1092. doi:10.2527/jas.2008-1608.

Yang, W. Z., C. Benchaar, B. N. Ametaj, and K. A. Beauchemin. 2010c. Dose response to eugenol supplementation in growing beef cattle: Ruminal fermentation and intestinal digestion. Anim. Feed Sci. Technol. 158:57-64. doi:10.1016/j.anifeedsci.2010.03.019. 